\title{
A coupled plankton-anchovy population dynamics model assessing nonlinear controls of anchovy and gelatinous biomass in the Black Sea
}

\author{
Temel Oguz*, Baris Salihoglu, Bettina Fach \\ Institute of Marine Sciences, Middle East Technical University, PO Box 28, Erdemli 33731, Mersin, Turkey
}

\begin{abstract}
A coupled model of lower trophic levels and anchovy Engraulis encrasicolus ponticus population dynamics was developed to analyze the mechanisms controlling sharp anchovy and gelatinous zooplankton biomass transitions from the 1960s to the 1980s in the Black Sea. An increase in anchovy stocks from estimated low ( 300 kt) to moderate $(\sim 700 \mathrm{kt})$ in the late $1960 \mathrm{~s}$ was related to weakening piscivore predation pressure, slight nutrient enrichment of the basin during an early eutrophication phase, and competitive exclusion of gelatinous carnivores. The transition to high stocks ( 1500 kt) from 1979 to 1980 was caused by additional nutrient enrichment. With enhanced enrichment, gelatinous carnivores started to coexist with anchovy at low biomass levels $\quad<1.0 \mathrm{gC}$ $\mathrm{m}^{-2}$ ), but they did not yet exert a strong control on anchovy because of their competitive disadvantage of consuming prey at low carrying capacity. The third transition (1989-1990) returned the anchovy stock to the low regime and increased the biomass of the alien gelatinous species Mnemiopsis leidyi (hereafter Mnemiopsis) to $3.0 \mathrm{gC} \mathrm{m}^{-2}$. The anchovy-Mnemiopsis shift was pre-conditioned by nutrient accumulation in the subsurface layer and triggered by their more effective transport into the productive surface layer following the switch of regional climate into a severe winter phase during 1985-1987. The resulting enhanced resource carrying capacity, together with decreasing adult anchovy stocks, led to a competitive advantage of Mnemiopsis in food exploitation relative to anchovy, growth and reproductive advantages relative to the native gelatinous species Aurelia aurita, and stronger predation on anchovy eggs and larvae. The anchovy stock depletion was caused by increasing fishing pressure and by competition with and predation by Mnemiopsis. While nonlinear coupling of these 2 independent processes amplified the anchovy collapse, neither would be able to individually impose such a severe anchovy stock change under the observed environmental conditions of the Black Sea.
\end{abstract}

KEY WORDS: Black Sea · Population dynamics · Trophic levels $\cdot$ Intraguild predation $\cdot$ Anchovy · Nutrient enrichment · Overfishing $\cdot$ Density-dependent feedbacks

Resale or republication not permitted without written consent of the publisher

\section{INTRODUCTION}

The Black Sea ecosystem has been subject to major structural transformations since the late 1960s (Zaitsev 1992, Vinogradov et al. 1996, Zaitsev \& Mamaev 1997, Kideys 2002, Sorokin 2002, Daskalov 2003, Bilio \& Niermann 2004, Oguz \& Gilbert 2007). In particular, pelagic fish stocks experienced marked decadal-scale fluctuations. Following over-exploitation of large pelagics, dolphins, and demersals towards the end of the 1960s, anchovy Engraulis encrasicolus ponticus (her- after anchovy) became the most abundant and commercially important target species, followed by sprat Sprat sprattus, the second in abundance (Daskalov 2003). Anchovy then began acting as the primary top predator and altered the previous trophic cascade in the lower trophic food web. As estimated from empirical catch data reported by Prodanov et al. (1997) and Ivanov \& Panayotova (2001), the period from the mid1960 s to the end of the 1970 s was characterized by an almost 4-fold increase in the anchovy stock (Fig. 1). Using the ECOPATH with ECOSIM (EwE) dynamic 
mass balance model, Daskalov (2002) confirmed a strong inverse relationship between changes in anchovy and apex predator stock sizes. Oguz (2007) further pointed to the nonlinear character of this transition. The high anchovy stock regime persisted for a decade and finally ended with the abrupt collapse in 1989-1990 (Fig. 1).

The period of marked anchovy stock changes also coincided with eutrophication of the Black Sea by an increasing rate of both organic and inorganic nutrient supply from the river Danube (Zaitsev \& Mamaev 1997). Summer phytoplankton biomass changed by an order of magnitude from $\sim 2.0 \mathrm{~g} \mathrm{~m}^{-2}$ in the 1960s to $\sim 20 \mathrm{~g} \mathrm{~m}^{-2}$ toward the end of the 1980s (Mikaelyan 1997; see also Fig. 3a in Oguz \& Gilbert 2007). Higher particulate export flux from the euphotic zone resulted in an increase of peak nitrate concentration in the chemocline layer (at depths around $75 \mathrm{~m}$ ) from ca. $2-3 \mu \mathrm{M}$ to $6-9 \mu \mathrm{M}$ in 2 decades (Fig. 2). Gelatinous zooplankton biomass increased from negligibly low values in the $1960 \mathrm{~s}$ to ca. $1.0 \mathrm{gC} \mathrm{m}^{-2}$ toward the end of the $1970 \mathrm{~s}$ and ca. $3.0 \mathrm{gC} \mathrm{m}^{-2}$ at the end of the $1980 \mathrm{~s}$ (Fig. 2). Prey zooplankton biomass had a variable response under concurrent bottom-up control of increased resource supply and top-down control of changing predation pressures (see Fig. $3 \mathrm{~b}$ in Oguz \& Gilbert 2007).

Modeling studies that substantiated the relative roles of ever-increasing eutrophication, heavy fishing, large reduction in top predator populations, and climate-induced variations, are limited. Using different configurations of the EwE model, Daskalov (2002) and Gücü (2002) showed how increasing fishing pressure and eutrophication indeed changed the Black Sea ecosystem. Berdnikov et al. (1999) embedded age-structured anchovy population dynamics into a complex food web structure and pointed to the critical importance of food competition with Mnemiopsis leidyi (hereafter refered to as Mnemiopsis) for the anchovy collapse. However, none of these models assessed the relative impacts of these mechanisms. For example, the controversy over whether the anchovy collapse took place first due to overfishing, and the Mnemiopsis population outbreak

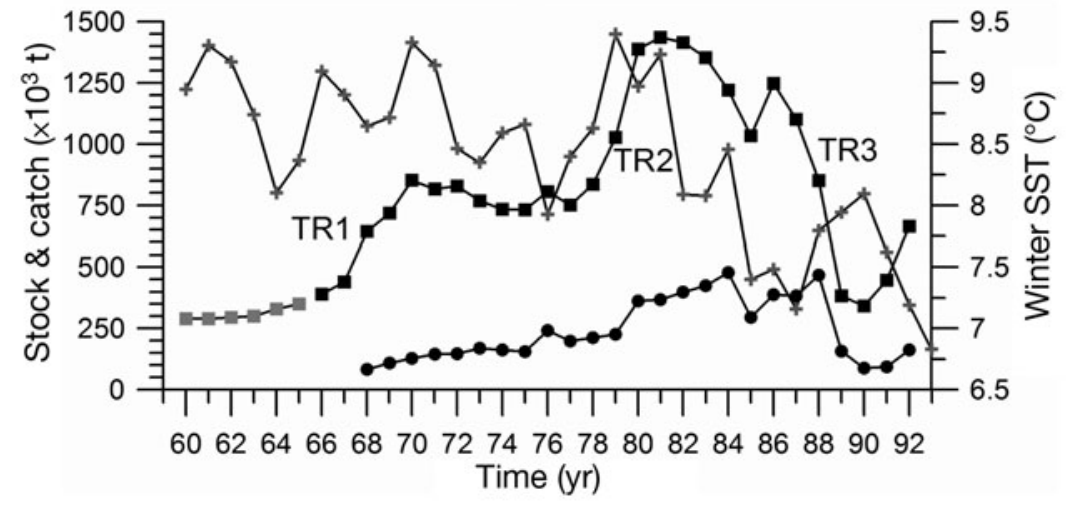

Fig. 1. Engraulis encrasicolus ponticus. (•) Time series of catch, (घ) exploitable stock at the beginning of the fishing season (October) as estimated by Prodanov et al. (1997), using the VPA method after 1966 and ( $\square$ ) Oguz (2007) before 1966 using a model. (+) Winter-mean sea surface temperature (SST). TR1, TR2, and TR3 denote transitions from low to moderate, moderate to high, and high to low regimes of anchovy stock, respectively. Numbers on the $x$-axis represent the last 2 digits of the year

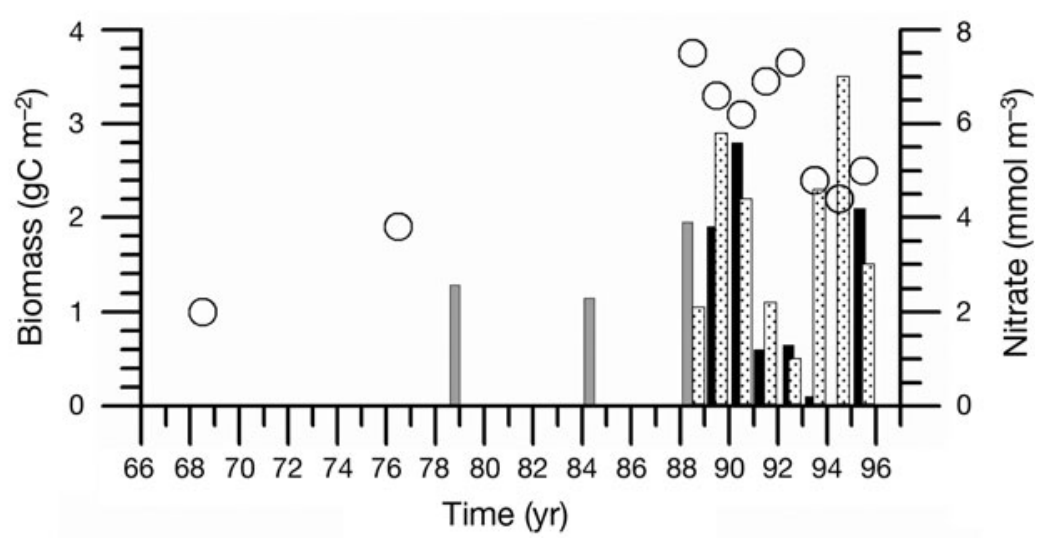

Fig. 2. Time series of total gelatinous biomass, dominated by Aurelia aurita (solid gray bars; annual-mean values) prior to 1989, and by Mnemiopsis leidyi from 1990 to 1996 (during spring: black bars; August-September: dotted bars). $O$ : peak nitrate concentration in the chemocline between the euphotic and the denitrification layers. Numbers on the $x$-axis represent the last 2 digits of the year. Gelatinous carnivore biomass data are based on measurements in the northeastern sector of the Black Sea (Shiganova et al. 2001). Nitrate data are taken from our institutional website at http://sfp1.ims.metu.edu.tr/ and represent the annual-mean of all available measurements excluding the northwestern shelf

followed the collapse or vice versa remains unresolved (Bilio \& Niermann 2004). Other food web modeling studies (e.g. Lebedeva \& Shushkina 1994, Oguz et al. 2001, Lancelot et al. 2002, Grégoire \& Lacroix 2003, Grégoire et al. 2004, Oguz \& Merico 2006, and the literature cited therein) did not include any higher trophic level dynamics and focused only on the impact of eutrophication and top-down gelatinous control on plankton structure and nutrient cycling. 
The present study brings together a lower trophic level (LTL) food web model with an anchovy population and bioenergetics-based weight growth model. From a fishery perspective, the coupled model offers a potential tool to examine reproduction, early life history, and recruitment dynamics of anchovy in response to changing environmental conditions and their internal feedbacks (e.g. Wang et al. 1997, Rose et al. 1999, Mullon et al. 2003). From an ecological perspective, explicitly modeled trophic interactions allow for the quantification and understanding of food web dynamics under differing bottom-up, top-down, and waspwaist controls during the re-organization phase of the Black Sea ecosystem (Oguz \& Gilbert 2007).

The present work puts less emphasis on a comprehensive description of anchovy life history characteristics (fishery perspective), and is mainly devoted to elucidating the mechanisms governing marked biomass changes of the anchovy-gelatinous prey-predator and competitor system from the late 1960s to the end of the 1980s (ecological perspective). The intraguild structure considered here comprises nutrients, plants, and detritus as the basal group; herbivorous microzooplankton and omnivorous mesozooplankton as the 2 resource groups; anchovy as the carnivorous consumer group; and gelatinous zooplankton as the carnivorous predator group preying both on anchovy eggs and larvae and the resource groups (Fig. 3). This structure is a

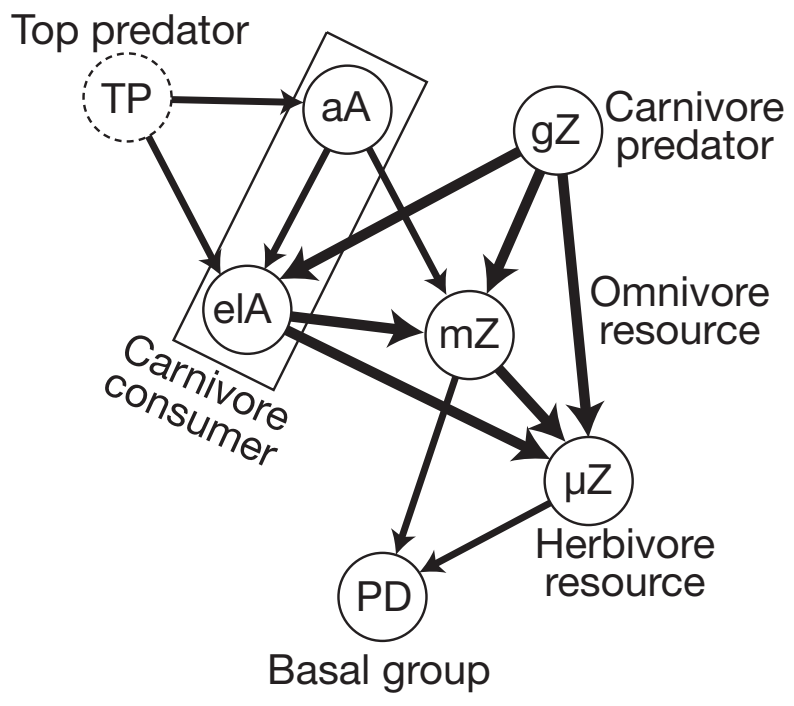

Fig. 3. Main elements and interactions in the omnivorous system formed by the basal group (plants and detritus: PD), the resource group (herbivorous microzooplankton: $\mu \mathrm{Z}$, and omnivorous mesozooplankton: $\mathrm{mZ}$ ), the carnivore consumer group (anchovy eggs and larvae: elA, and adult anchovy: aA), the carnivore predator group (gelatinous zooplankton: gZ), and top predator group (pelagic piscivores: TP). Arrows are directed from predators to prey. Thick arrows represent the primary trophic interactions of the IGP system that are critical in terms of anchovy-gelatinous shift more complex version of the classical 3-component intraguild system that was studied for its stability properties (Holt \& Polis 1997, Hart 2002, Revilla 2002) and response characteristics to changing resource carrying capacity (Diehl \& Feibel 2000, Mylius et al. 2001, Kuijper et al. 2003, van de Wolfshaar et al. 2006). Gelatinous predation on anchovy eggs and larvae may be interpreted as the wasp-waist control (Bakun 2006).

The subsequent sections first describe the model formulation and corroboration of the model results with available data. A suite of model simulations is then presented to seek quantitative support for the hypothesis that the 3 marked changes in anchovy stocks (TR1, TR2, and TR3 in Fig. 1) and the abrupt Mnemiopsis biomass increase accompanying TR3 (Fig. 2) characterize nonlinear responses of the food web to multiple exogenous forcings and their densitydependent biological feedbacks among the components of the intraguild system. Finally, we interpret our findings within the context of general theory of intraguild interactions and the observed Black Sea ecosystem changes.

\section{METHODS}

The model simultaneously solves a set of 1-dimensional equations for a coastal environment (the southeastern Black Sea) where anchovy and gelatinous carnivores reproduce, grow, and forage favorably and where the majority of the anchovy fishery is located (Mutlu et al. 1994, Niermann et al. 1994, Kideys et al. 1999). The assumption of horizontal uniformity that is implict in a 1-dimensional model is probably unrealistic given the complex mesoscale variability of the system and dependence of anchovy and gelatinous carnivore life history characteristics on physical conditions (Panov \& Chashchin 1990, Mutlu et al. 1994, Niermann et al. 1994, Kideys et al. 1999). However, it is an essential first step to explore and understand the model dynamics before introducing additional spatial complexity to the problem.

Vertical model structure. The vertical model structure extends from the surface to the upper part of the chemocline. It comprises the biologically active euphotic layer and the subsequent nitrate source layer, which is biologically inactive for the purpose of this model and only supplies nitrate flux into the euphotic layer through vertical diffusive and convective exchanges. The euphotic zone is further divided into 2 layers, the surface mixed layer $\left(h_{1}\right)$ and the subthermocline layer $\left(h_{2}\right)$. This 2-layer structure is a simple but adequate configuration to incorporate the effect of thermal stratification: the shallow mixed layer with the permanent cold layer beneath in summer and 
the deepening of the mixed-layer in autumn and winter. The nitrate source layer constitutes the upper portion of the chemocline where nutrients accumulate due to aerobic remineralization of organic material above the denitrification-suboxic layer of the water column (Konovalov \& Murray 2001). The rest of the chemocline layer is located below the active turbulent mixing zone and normally does not affect biological production in the surface layer. Using the same vertical structure, a slightly more complex food web structure reproduced major features of the observed annual plankton dynamics (e.g. surface-intensified spring and autumn primary and secondary productions and sub-surface summer productions) during the intense eutrophication period of the Black Sea ecosystem (Oguz et al. 2001).

Description of LTL model structure. The LTL food web structure is a relatively simplified version of the model described by Oguz et al. (2001). It involves the 3 most dominant phytoplankton functional groups $\left(\mathrm{P}_{1}\right.$, diatoms; $\mathrm{P}_{2}$, dinoflagellates; $\mathrm{P}_{3}$, small phytoplankton) and 3 zooplankton functional groups $\left(Z_{1}\right.$, mesozooplankton; $Z_{2}$, microzooplankton; $Z_{3}$, gelatinous carnivores). The coccolithophore Emiliania huxleyi, which forms part of the observed phytoplankton species succession in May-July (Cokacar et al. 2003), was excluded due to its limited role in resource supply to higher trophic levels.

The moon jelly Aurelia aurita (hereafter refered to as Aurelia) was the most dominant gelatinous species in the Black Sea from the 1970s to the late 1980s, before Mnemiopsis was present in the Black Sea (Shushkina \& Musayeva 1983). The ctenophore Mnemiopsis reached the Black Sea from the east coast of the United States during the early 1980 s, acclimated to local conditions during the mid-1980s, and suddenly and abruptly acquired a biomass 2 to 3 times higher than Aurelia at the end of the 1980s (Vinogradov et al. 1989). The gelatinous group of the model therefore represents medusae of Aurelia until the end of the 1980s and Mnemiopsis afterward. This simplified representation may be justified on the premise that Aurelia and Mnemiopsis have comparable growth and mortality rates (Shushkina \& Musayeva 1983, Shushkina et al. 1998), and the gelatinous group in the Black Sea was always dominated by either species. The difference essentially stems from their different reproduction and life history characteristics, which were not resolved in the present study.

The reproduction and feeding characteristics of Mnemiopsis give them a competitive advantage over Aurelia (Finenko et al. 1995, Purcell et al. 2001). Aurelia females harbor fertilized eggs, and the larvae settle on hard substrates in oxygenated near-shore waters to become polyps. Benthic polyps bud small (1-2 mm) medusae that grow in spring and reach a sexually mature adult stage in summer (Lucas 2001). By contrast, the survivors of the overwintering Mnemiopsis population shed gametes directly into the surrounding water within the upper mixed layer when conditions improve and fertilization takes place (Martindale 1987, Kremer \& Reeve 1989).

Nitrate constitutes the only abiotic compartment in this simplified model. Nitrate concentration $\left(N_{\mathrm{c}}\right)$ is linked to the plankton compartments by partial recycling of detritus flux within the euphotic zone as well as by supply from the subsurface source layer through vertical turbulent exchanges. The nitrogen cycle incorporates neither bacterially-mediated remineralization of particulate organic nitrogen nor a subsequent transformation of the labile fraction of dissolved organic nitrogen (DON) into ammonium and then nitrate. Instead, the model assumes immediate conversion of part of the detritus into nitrate, whereas the rest is lost to deeper layers. The model configuration therefore compromises between simplicity in terms of overall food web representation and complexity in terms of its critical processes controlling the food web structure for the problem under consideration.

Mathematical formulation of the LTL model. The governing equations of the LTL model are given in compact notation by

$$
\begin{aligned}
& \frac{d \mathrm{P}_{i, \mathrm{k}}}{d t}=U_{i, \mathrm{k}}-G_{\mathrm{Z} 1, \mathrm{k}}^{\mathrm{P}_{\mathrm{i}}}-G_{\mathrm{Z} 2, \mathrm{k}}^{\mathrm{Pi}}-m_{P_{i}} \mathrm{P}_{i, \mathrm{k}}+M_{\mathrm{k}}^{\mathrm{P} i} \\
& \frac{d \mathrm{Z}_{1, k}}{d t}=\varepsilon_{\mathrm{Z} 1}\left[\sum_{i=1}^{3} G_{\mathrm{Z} 1, \mathrm{k}}^{\mathrm{Pi}}+G_{\mathrm{Z} 1, \mathrm{k}}^{\mathrm{Z1}}\right]-G_{\mathrm{Z} 3, \mathrm{k}}^{\mathrm{Z} 1}-\underline{\tilde{C}_{A, \mathrm{k}}^{\mathrm{Z} 1}}-m_{\mathrm{Z} 1} \mathrm{Z}_{1, \mathrm{k}}+M_{\mathrm{k}}^{\mathrm{Z1}} \\
& \frac{d \mathrm{Z}_{2, \mathrm{k}}}{d t}=\varepsilon_{\mathrm{Z} 2} \sum_{i=1}^{3} G_{\mathrm{Z} 2, \mathrm{k}}^{\mathrm{P}_{\mathrm{i}}}-G_{\mathrm{Z} 1, \mathrm{k}}^{\mathrm{Z} 2}-G_{\mathrm{Z} 3, \mathrm{k}}^{\mathrm{Z} 2}-\underline{\tilde{C}_{A, \mathrm{k}}^{\mathrm{Z} 2}}-m_{\mathrm{Z} 2} \mathrm{Z}_{2, \mathrm{k}}+M_{\mathrm{k}}^{\mathrm{Z}} \\
& \frac{d \mathrm{Z}_{3, k}}{d t}=\varepsilon_{\mathrm{Z} 3}\left[\underline{\underline{\tilde{G}_{\mathrm{Z}, k=1}^{\mathrm{A}}}}+\sum_{i=1}^{2} G_{\mathrm{Z} 3, \mathrm{k}}^{\mathrm{Zi}}\right]-m_{Z_{3}} \mathrm{Z}_{3, k}+\kappa_{\mathrm{Z}_{3}}\left(\mathrm{Z}_{3, \mathrm{k}}^{S}-\mathrm{Z}_{3, k}\right)+M_{\mathrm{k}}^{\mathrm{Z3}} \\
& \text { Det_flux }=\left(1-\varepsilon_{\mathrm{Z}_{1}}\right)\left[G_{\mathrm{Z} 1, k}^{\mathrm{Z} 2}+\sum_{i=1}^{3} G_{\mathrm{Z}, 1, k}^{\mathrm{pi}}\right]+\left(1-\varepsilon_{\mathrm{Z}_{2}}\right) \sum_{i=1}^{3} G_{\mathrm{Z}_{1}, k}^{\mathrm{pi}} \\
& \left(1-\varepsilon_{\mathrm{Z} 3}\right)\left[\underline{\underline{\tilde{G}_{\mathrm{Z} 3, k=1}^{\mathrm{A}}}}+\sum_{i=1}^{2} G_{\mathrm{Z} 3, \mathrm{k}}^{\mathrm{Zi}}\right]+\left(1-\varepsilon_{\mathrm{A}}\right) \underline{\left(\tilde{C}_{\mathrm{A}, \mathrm{k}}^{\mathrm{Z} 1}+\tilde{C}_{\mathrm{A}, k}^{\mathrm{Z} 2}\right)} \\
& \frac{d N_{k}}{d t}=-\sum_{i=1}^{3} U_{i, k}+\alpha\{\text { Det_flux }\}+\sum_{i=1}^{3} m_{Z i} Z_{i, k}+\sum_{i=1}^{3} m_{P i} P_{i, k}+M_{k}^{N c}
\end{aligned}
$$

Eq. (1a-f) applies for both layers of the euphotic zone $(k=1,2)$; explicit forms of all terms are documented in the Appendix, and the definitions of parameters and their values are listed in Tables 1 to 4 . Underlined and double-underlined terms are referred to in the following sections. The operator $d / d t$ represents the time derivative; $P_{i}$ and $Z_{i 1}$ respectively, denote any of the 3 phytoplankton and zooplankton groups; and $N_{\mathrm{c}}$ is the nitrate concentration. Det_flux denotes the detritus flux, comprised of the unassimilated fraction of food consumption 
Table 1. Parameters of phytoplankton groups

\begin{tabular}{|c|c|c|c|c|c|}
\hline $\begin{array}{l}\text { Para- } \\
\text { meter }\end{array}$ & Definition & Unit & Diatoms & $\begin{array}{l}\text { Dino- } \\
\text { flagellates }\end{array}$ & $\begin{array}{c}\text { Small } \\
\text { phyto- } \\
\text { plankton }\end{array}$ \\
\hline$r_{\mathrm{P}_{\mathrm{i}}}$ & Maximum growth rate & $\mathrm{d}^{-1}$ & 2.5 & 1.3 & 1.65 \\
\hline$K_{\mathrm{N}}$ & $\begin{array}{l}\text { Half saturation con- } \\
\text { stant for nitrate uptake }\end{array}$ & $\mathrm{mmol} \mathrm{m}^{-3}$ & 0.5 & 0.23 & 0.3 \\
\hline$m_{P_{i}}$ & Mortality rate & $d^{-1}$ & 0.04 & 0.03 & 0.05 \\
\hline$v_{\mathrm{P}}{ }^{1}$ & $\begin{array}{l}\text { Exchange rate between } \\
\text { layers }\end{array}$ & $d^{-1}$ & 0.01 & 0.01 & 0.01 \\
\hline
\end{tabular}

Table 2. Parameters of zooplankton groups

\begin{tabular}{|llcccc|}
\hline $\begin{array}{l}\text { Para- } \\
\text { meter }\end{array}$ & Definition & Unit & $\begin{array}{c}\text { Microzoo- } \\
\text { plankton }\end{array}$ & $\begin{array}{c}\text { Mesozoo- Gelatinous } \\
\text { plankton }\end{array}$ \\
\hline$r_{\mathrm{Z}_{\mathrm{i}}}$ & Maximum growth rate & $\mathrm{d}^{-1}$ & 1.8 & 1.0 & 0.05 \\
$K_{\mathrm{Z}}$ & $\begin{array}{l}\text { Half saturation } \\
\text { constant for phyto- }\end{array}$ & & & & - \\
& $\begin{array}{l}\mathrm{mmol} \mathrm{m}^{-3} \\
\text { plankton grazing }\end{array}$ & & 0.6 & 0.6 & \\
$m_{\mathrm{Z}_{\mathrm{i}}}$ & Mortality rate & $\mathrm{d}^{-1}$ & 0.06 & 0.04 & 0.008 \\
$\mathrm{v}_{\mathrm{Z}}$ & Vertical migration rate & $\mathrm{d}^{-1}$ & 0.01 & 0.01 & 0.01 \\
$\varepsilon_{\mathrm{Z}_{\mathrm{i}}}$ & Assimilation efficiency & Unitless & 0.5 & 0.5 & 0.6 \\
\hline
\end{tabular}

Table 3. Food preference coefficients, indicating preferences of different predator groups for certain prey groups

\begin{tabular}{|lcccc|}
\hline Prey type & $\begin{array}{c}\text { Microzoo- } \\
\text { plankton }\end{array}$ & $\begin{array}{l}\text { Mesozoo- Gelatinous } \\
\text { plankton }\end{array}$ & Anchovy \\
\hline Diatoms & 0.2 & 0.4 & & \\
$\begin{array}{l}\text { Dinoflagellates } \\
\text { Small phyto- }\end{array}$ & 0.2 & 0.3 & & \\
$\begin{array}{l}\text { plankton } \\
\text { Microzooplankton } \\
\text { Mesozooplankton }\end{array}$ & 0.6 & 0.1 & & \\
\hline
\end{tabular}

of 3 zooplankton groups and all anchovy age classes. All state variables are expressed in mmol $\mathrm{N} \mathrm{m}^{-3}$.

According to Eq. (1a), the biomass density for any phytoplankton group changes in time due to growth $\left(U_{\mathrm{i}}\right.$; Eq. A1 in the Appendix), grazing by micro- and mesozooplankton groups $\left(G_{\mathrm{Z}_{j}}^{\mathrm{P}_{i}}\right.$ Eq. A6a,b) mortality $\left(m_{\mathrm{P}_{i}}\right)$, and vertical exchange between the layers $\left(M^{\mathrm{P}_{i}}\right.$ i Eq. A8). In the growth term, the maximum growth rate, $r_{\mathrm{P}_{i^{\prime}}}$ is reduced by products of nutrient, light, and temperature limitation functions (Eqs. A2-A5). In Eq. (1b, c), meso- and microzooplankton biomass densities change temporally due to ingestion of phytoplankton, consumption by total gelatinous carnivores $\left(\tilde{G}_{\mathrm{Z} 3}^{\mathrm{Zi}}\right.$ i Eqs. 8 \& A7) and by all cohorts of the age-0 age class and the older age classes of the anchovy population ( $\left.\tilde{C}_{\mathrm{A}}^{\mathrm{Zi}} ; \mathrm{Eq} .7 \mathrm{a}, \mathrm{b}\right)$, mortality $\left(m_{\mathrm{Z}_{i}}\right)$, and vertical migration between the layers $\left(M^{Z_{i}}\right.$; Eq. A8), respectively. Mesozooplankton graze on microzooplankton $\left(\tilde{G}_{\mathrm{Z} 3, k=1}^{\mathrm{A}}\right)$; Eq. A6c) as well.

Gelatinous biomass changes over time (Eq. 1d) through their feeding on anchovy eggs and larvae $\tilde{G}_{\mathrm{Z} 3, k=1}^{\mathrm{A}}$, microzooplankton and mesozooplankton $\left(\tilde{G}_{\mathrm{Z} 3}^{\mathrm{Zi}}\right)$, losses due to natural mortality, and exchange between the layers due to vertical migration ( $M^{\mathrm{Z}_{3}}$; Eq. A9). The additional source term parameterizes lateral transport of young gelatinous species biomass $\left(Z_{3, k}^{S}\right)$ grown in near-shore regions into the model domain via the regional circulation system with the transport rate $\kappa_{\mathrm{Z} 3}$.

Table 4. Additional parameter values of the lower trophic level (LTL) model

\begin{tabular}{|c|c|c|c|}
\hline Parameter & Definition & Unit & Value \\
\hline$a_{\mathrm{I}}$ & Initial slope of the $\mathrm{P}-\mathrm{I}$ curve of light limitation & $\mathrm{m}^{2}$ watts $^{-1}$ & 0.01 \\
\hline$k_{\mathrm{w}}$ & Phytoplankton exctinction coefficient for clear water conditions & $\mathrm{m}^{-1}$ & 0.08 \\
\hline$k_{\mathrm{c}}$ & Phytoplankton-biomass-dependent extinction coefficient & $\mathrm{m}^{-1}$ & 0.02 \\
\hline$h_{\mathrm{e}}$ & Euphotic layer depth & $\mathrm{m}$ & 50.0 \\
\hline$T_{\max }$ & Maximum temperature of the limitation function of phytoplankton and zooplankton growth & ${ }^{\circ} \mathrm{C}$ & 25 \\
\hline$T_{\text {Pref }}$ & Reference temperature of the phytoplankton limitation function & ${ }^{\circ} \mathrm{C}$ & 15 \\
\hline$T_{\mathrm{Z}_{\mathrm{ref}}}$ & Reference temperature of the zooplankton limitation function & ${ }^{\circ} \mathrm{C}$ & 13 \\
\hline$Q_{10 \mathrm{P}}$ & $Q_{10}$ factor of temperature limitation on phytoplankton growth & unitless & 1.5 \\
\hline$Q_{10 z}$ & $Q_{10}$ factor of temperature limitation on zooplankton growth & unitless & 2.2 \\
\hline$\alpha$ & Recycled fraction of zooplankton and anchovy ingestion & unitless & 0.2 \\
\hline$v_{N_{\mathrm{C}}}$ & Diffusion rate of nitrate between the layers & $d^{-1}$ & 0.01 \\
\hline$W_{e, \max }$ & Maximum value of the nitrate entrainment rate between the layers & $\mathrm{d}^{-1}$ & 0.04 \\
\hline$r_{\mathrm{Z}_{3}}^{A}$ & Consumption rate of anchovy eggs and larvae by gelatinous carnivores & $\mathrm{m}^{3} \mathrm{mgC}^{-1} \mathrm{~d}^{-1}$ & 0.05 \\
\hline$K_{\mathrm{Z}_{3}}$ & Slope factor of gelatinous carnivores feeding on micro- and mesozooplankton & $\mathrm{mmol} \mathrm{N} \mathrm{m}{ }^{-3}$ & 0.24 \\
\hline
\end{tabular}


However, this contribution occurs only when the mixed layer temperature exceeds $15^{\circ} \mathrm{C}$. Below this threshold temperature, gelatinous production does not take place either within the model domain or in near-shore regions. Because the model focuses on conditions prior to the settlement of Beroe ovata into the Black Sea, no Beroe ovata predation on Mnemiopsis was introduced. Neither Aurelia nor Mnemiopsis have predators in the model, and they are the dead-end of the food web.

The parameters denoted by $\varepsilon_{\mathrm{Z} 1}, \varepsilon_{\mathrm{Z} 2}, \varepsilon_{\mathrm{Z} 3}$ in Eq. (1b-d) represent the fractions of food digested and assimilated by the zooplankton groups after all excretion and respiratory losses, expressed by constant proportions of the consumption, are removed. They convey the product of a food digestion coefficient (about 70 to $80 \%$ ) and a food assimilation coefficient (about 70 to $75 \%$ ).

$N_{\mathrm{c}}$ in the surface mixed and sub-thermocline layers varies temporally (Eq. 1f) due respectively to its uptake in phytoplankton growth, recycling of unassimilated food and of dead planktonic material, vertical diffusion, and entrainment between the layers and from the subsurface source layer, $M_{k}^{N}$ (Eq. A9).

According to Eq. (1f), nitrate recycles partially within the euphotic layer, and the rest constitutes total export flux to deep layers. As stated earlier, the remineralization process is not modeled explicitly. Instead, this process is assumed to be responsible for long-term nitrate accumulation in the chemocline layer under intensifying eutrophication (Fig. 2). It is characterized in the model by the subsurface nitrate concentration $\left(N_{\mathrm{c}}\right)$ prescribed externally as one of the control (forcing) variables in the model. Its product with the sum of diffusion and entrainment rates specifies the $N_{\mathrm{C}}$ supplied from the source layer into the euphotic zone that drives the nutrient cycling and biological production in the model (Eq. A9). Since the model assumes no active biology in the source layer, no phytoplankton and zooplankton flux is specified from the source layer into the euphotic zone (see Eq. A8).

The terms underlined in Eq. (1b-d), which mark micro- and mesozooplankton consumption by anchovy and gelatinous carnivores and recycled fractions of their unassimilated forms, constitute the dynamic linkage between the LTL and anchovy models.

Description of the higher trophic level model structure. The Black Sea anchovy is known for its extraordinarily high fecundity, long spawning season (May to September), and opportunistic feeding on a wide selection of micro- and mesozooplankton types (Lisovenko \& Andrianov 1996) compared to other anchovy species in different parts of the world (Alheit 1989, Castro \& Cowen 1991, Millan 1999, Funamoto et al. 2004, North \& Houde 2004, Basilone et al. 2006, Palomera et al. 2007). In general, it has the ability to adapt its reproductive characteristics (e.g. batch fecundity, spawning frequency, age/length at first maturity) to changing environmental conditions. Its high food consumption capability, even during the spawning season, provides sufficient energy to support all expenses of basal metabolism, somatic growth, and active reproduction. It can feed continuously day and night if prey is available (Bulgakova 1996). It grows rapidly, matures early (within the first year), shows schooling behavior especially during the spawning season, and is characterized by high swimming activity and active seasonal migration to more productive areas for overwintering. The size and weight of adults vary in the range of 8 to $15 \mathrm{~cm}$ and 5 to $21 \mathrm{~g}$ wet weight (gww), depending on environmental conditions and age.

Female adults spawn most efficiently in June to August when water temperatures exceed $20^{\circ} \mathrm{C}$, and the optimum temperature is around $23-25^{\circ} \mathrm{C}$ (Niermann et al. 1994, Lisovenko \& Andrianov 1996, Sorokin 2002). In the higher trophic level (HTL) model, hereafter anchovy model, the anchovy spawning season begins on 1 June, even though temperature of the mixed layer may be slightly less than $20^{\circ} \mathrm{C}$, depending on the annual mixed layer temperature structure. The spawning period lasts until the end of August and therefore comprises $90 \mathrm{~d}$ (each month is assumed to be $30 \mathrm{~d}$ ).

Temperature is a critical factor during anchovy early life stages (Garcia \& Palomera 1996, Lisovenko \& Andrianov 1996, North \& Houde 2004). In the Black Sea, eggs and larvae are always found above the seasonal thermocline (in the upper 15 to $20 \mathrm{~m}$ ), and egg production is not possible within the cold intermediate layer $\left(\sim 7^{\circ} \mathrm{C}\right)$ below the surface mixed layer (Niermann et al. 1994, Kideys et al. 1999, Satilmis et al. 2003). In the model, population dynamics of the early life stages were therefore limited to the surface mixed layer. However, juvenile, young of the year (YoY), and adult anchovy may follow the vertical migration of zooplankton prey and are likely distributed more uniformly within the euphotic zone. The anchovy model treats the entire euphotic zone as a single layer system for post-larval populations in order to avoid the difficulty of parameterizing their vertical movement and feeding on herbivores.

Eggs spawned each day of the spawning season are followed as a specific cohort through hatching, yolksac larva, early larva, late larva, juvenile, and YoY stages of the age-0 class. According to observations, the pre-larval period lasts for about 2.0 to $2.5 \mathrm{~d}$ at water temperatures above $20^{\circ} \mathrm{C}$ (Lisovenko \& Andrianov 1996). For simplicity, the model assumes a $1 \mathrm{~d}$ constant developmental period for both hatching and yolk-sac larval phases with no temperature dependence. Larvae are assumed to begin feeding on microzooplankton $2 \mathrm{~d}$ after hatching in the early larval phase (up to $\sim 1.0 \mathrm{~cm}$ length) and in the late larval phase (up to 
$2.5 \mathrm{~cm})$. Larvae metamorphose into juveniles at $2.5 \mathrm{~cm}$, juveniles become YoY at $4.0 \mathrm{~cm}$, and YoY individuals reach sexual maturity at $6.0 \mathrm{~cm}$ (Lisovenko \& Andrianov 1996). Under typical conditions, the early larval stage spans $12 \mathrm{~d}$, the late larval stage is about $22 \mathrm{~d}$, and the juvenile stage lasts about 32 d (Sorokin 2002).

All individuals hatched on the same day are considered to belong to the same cohort. The model thus specifies 90 daily cohorts every year. The members of each cohort have identical life histories, but population and size of cohorts vary over the course of the year depending on internal and external conditions. At the beginning of June (i.e. the start of the new spawning season), the sum of recruits from all 90 cohorts is assigned to the population of the age-1 class, and the mean weight of all cohorts is assigned to the weight of the age-1 class. Other age classes are similarly promoted to the next higher age classes: yearlings become age-2, age- 2 become age-3. Any older individuals are retained in the age- 3 class. The anchovy population can live for up to $4 \mathrm{yr}$, but they often do not survive more than 2 yr due to high fishing mortality.

Mathematical formulation of the population growth model: The total number of healthy eggs produced daily in the mixed layer by female adults in age-1 to age-3 classes during June to August is parameterized according to

$$
X_{\mathrm{e}}=\left[\sum_{i=1}^{3} S \times E_{\mathrm{g}} \times\left(\frac{1}{2} X_{i} \times W_{i}\right) \times f_{\mathrm{e}}\left(T_{1}\right) / w_{\text {egg }}\right]+X_{\mathrm{oe}}
$$

where $X_{i}$ and $W_{i}(i=1-3)$ denote population density and weight of an individual anchovy in adult age classes, respectively, $E_{\mathrm{g}}$ signifies the daily weight loss rate of mature female adults for egg production, $S$ is the efficiency of healthy eggs produced, $w_{\text {egg }}$ is the individual egg weight (Table 5), and $f_{\mathrm{e}}\left(T_{1}\right)$ is the temperature dependence of egg production that is expressed by a $Q_{10}$ type function (similar to Eq. A5) and varies between 0.70 at $20^{\circ} \mathrm{C}$ and 1.0 at $25^{\circ} \mathrm{C}$. $X_{\mathrm{oe}}$ represents a constant number of eggs $\left(0.5\right.$ eggs $\left.\mathrm{m}^{-3}\right)$ produced daily, independent of anchovy population

Table 5. Parameter values of the anchovy model

\begin{tabular}{|llcl|}
\hline \multirow{2}{*}{ Parameter } & \multicolumn{1}{c}{ Definition } & Unit & Value \\
\hline$\varepsilon_{\mathrm{A}}$ & $\begin{array}{l}\text { Fraction of consumption available for } \\
\text { anchovy growth }\end{array}$ & unitless & 0.5 \\
$b_{1}$ & Weight-length conversion factor & $\mathrm{cm}$ & 5.0 \\
$b_{2}$ & Exponent of weight-length conversion & unitless & 0.333 \\
$W_{\text {egg }}$ & Egg weight & mgC & 0.02 \\
$S$ & Spawning efficiency of female adults & unitless & 0.22 \\
$E_{\mathrm{g}}$ & Weight loss rate of a female adult on the & $\mathrm{d}^{-1}$ & 0.10 \\
& day of spawning & unitless & 90 \\
\hline
\end{tabular}

and biomass in the model domain. This background value helps to introduce a cohort even when the mixed layer temperature may be less than $20^{\circ} \mathrm{C}$ between 1 and 15 June (according to the annual climatological temperature annual cycle).

Eq. (2) relates anchovy egg production to mixed layer temperature and population and body size of adult females, which then links reproduction to feeding conditions (Eq. 4, under 'Mathematical formulation of the weight growth model' below) and ultimately to the intensity of bottom-up resource control. Therefore, spawning and early life history characteristics are expected to respond differently to developing eutrophication and climatic conditions at interannual and longer time scales. This density-dependent population growth mechanism is a central focus of the simulations described in the next section. In the present study, the temperature control in Eq. (2) considers only intraannual variations without interannual changes.

The population density $\left(X_{\mathrm{A}}\right.$ ind. $\mathrm{m}^{-3}$ ) of any anchovy cohort of the age- 0 class or each of the adult age classes changes with time according to

$$
\frac{d X_{\mathrm{A}}}{d t}=-\left(m_{\mathrm{f}}+m_{\mathrm{n}}\right) X_{\mathrm{A}}
$$

where $m_{\mathrm{f}}$ and $m_{\mathrm{n}}$ denote the fishing and natural mortality rates, respectively. The natural (predation) mortality rate is expressed by

$$
m_{\mathrm{n}}=m_{\mathrm{b}}+m_{1} X_{\mathrm{A}}+r_{\mathrm{Z} 3}^{\mathrm{A}} \mathrm{Z}_{3, k=1}
$$

that comprises the sum of linear and quadratic contributions (Fulton et al. 2003, Tian et al. 2004). The first term (hereafter referred to as the basal mortality with the rate constant $m_{\mathrm{b}}$ ) represents stable or average environmental conditions and varies for different life stages (Table 6). It also includes all other non-predatory losses. The quadratic, density-dependent components involve the predation mortalities due to (1) predation by large and medium pelagics and demersals (the second term) that are not explicitly included in the model and increase with anchovy population size at the rate constant, $m_{1}$, and (2) the gelatinous carnivore (the last term) that operates only for the eggs and larval population $(<2.5 \mathrm{~cm})$ in the surface mixed layer. The parameter $r_{\mathrm{Z} 3}^{\mathrm{A}}$ denotes the time-dependent clearance rate of gelatinous species $\left(\mathrm{m}^{3} \quad \mathrm{mgC}^{-1} \mathrm{~d}^{-1}\right)$ (Table 4 ), and $Z_{3, k=1}$ is the gelatinous biomass density in the mixed layer. The predation mortality parameterization of the gelatinous group does not include processes such as predator encounter rates, probability of attack, capture efficiency, predator size, prey (anchovy) 
Table 6. Anchovy model parameters for different stages of weight growth. YoY: young of the year

\begin{tabular}{|c|c|c|c|c|c|c|c|}
\hline Parameter & Definition & Unit & $\begin{array}{l}\text { Early } \\
\text { larva }\end{array}$ & $\begin{array}{l}\text { Late } \\
\text { larva }\end{array}$ & Juvenile & YoY & Adul \\
\hline$m_{\mathrm{b}}$ & Basal mortality rate ${ }^{\mathrm{a}}$ & $\mathrm{d}^{-1}$ & 0.3 & 0.1 & 0.02 & 0.007 & 0.002 \\
\hline$C_{1}$ & Maximum consumption rate & $\mathrm{mgC} \mathrm{d}^{-1}$ & 1.23 & 0.93 & 0.65 & 0.49 & 0.33 \\
\hline$C_{2}$ & Weight dependence of consumption & unitless & 0.27 & 0.30 & 0.31 & 0.32 & 0.32 \\
\hline$r_{1}$ & Maximum respiration rate & $\mathrm{mgC} \mathrm{d}^{-1}$ & 0.022 & 0.022 & 0.025 & 0.028 & 0.028 \\
\hline$r_{2}$ & Weight parameter of respiration & unitless & 0.34 & 0.34 & 0.34 & 0.34 & 0.34 \\
\hline$K_{\mathrm{ZA}}$ & $\begin{array}{l}\text { Half saturation constant of anchovy } \\
\text { feeding on zooplankton }\end{array}$ & $\mathrm{mgC} \mathrm{m}^{-3}$ & 135 & 135 & 170 & 225 & 225 \\
\hline $\mathrm{A}_{F}$ & Activity factor of respiration & unitless & 1.5 & 1.5 & 1.5 & 1.5 & 1.5 \\
\hline
\end{tabular}

size and abundance, and presence of alternative food (Cowan et al. 1996, Purcell \& Arai 2001).

The model also incorporates starvation (weight dependent) mortality that may occur when prey availability is not sufficient to maintain basic metabolic requirements (i.e. $d W / d t<0$ in Eq. 4) (e.g. in winter). Following Rose et al. (1999), starvation mortality applies whenever the weight loss exceeds $35 \%$ for larvae and $50 \%$ for post-larval stages with respect to the weight expressed by the length-weight relationship. A particular year class population subject to starvation loses weight, but not length. Eq. $(3 a, b)$ forms a closed system with no source/sink due to the migration mechanism.

Mathematical formulation of the weight growth model: The bioenergetics-based anchovy weight growth model follows Luo \& Brandt (1993), Rose et al. (1999), McDermot \& Rose (2000), and Megrey et al. (2007). No weight growth occurs in egg and yolk-sac larval phases of each daily cohort. By the beginning of the early larval phase, individuals of each cohort start feeding and become subject to weight growth following

$$
\frac{d W_{\mathrm{A}}}{d t}=\left(\varepsilon_{\mathrm{A}} C_{\mathrm{A}}-R_{\mathrm{A}}-E_{\mathrm{g}}\right) \times W_{\mathrm{A}}
$$

where $W_{\mathrm{A}}\left(\mathrm{mgC}\right.$ ind.$\left.^{-1}\right)$ denotes weight of an individual anchovy for any cohort of the age-0 class. The same equation also applies to the adult age classes. The right hand side of Eq. (4) describes the difference between the realized consumption rate $\left(\varepsilon_{\mathrm{A}} C_{\mathrm{A}}\right)$, the losses due to total respiration $\left(R_{\mathrm{A}}\right)$, and the weight loss rate due to reproduction by sexually mature $(>6.0 \mathrm{~cm})$ female individuals $\left(E_{\mathrm{g}}\right)$, all expressed per day $\left(\mathrm{d}^{-1}\right)$. The parameter $\varepsilon_{\mathrm{A}}$ denotes the fraction of the consumption rate used for growth after losses due to egestion, excretion, and specific dynamic action (i.e. the energy loss associated with food digestive processes) are subtracted (Table 5). Each of these losses accounts for a constant proportion of the consumption rate, and all together typically amount to $50 \%$ (Rose et al. 1999, Megrey et al. 2007). The variable $C_{\mathrm{A}}$ represents the consumption of herbivorous zooplankton $\left(C_{\mathrm{A}}^{\mathrm{Z}_{1}}\right)$ and omnivorous zoo- plankton $\left(C_{\mathrm{A}}^{\mathrm{Z}_{2}}\right)$ by an individual anchovy. They are expressed in terms of the maximum consumption rate $C_{1}$ (mg $\mathrm{C} \mathrm{d}^{-1}$ ), anchovy weight, water temperature, and mesozooplankton and microzooplankton biomass density by

$$
C_{\mathrm{A}}^{\mathrm{Z}_{i}}=C_{1} \times W_{\mathrm{A}}^{-C_{2}} \times f(T) \times f\left(\overline{\mathrm{Z}}_{i}\right)
$$

where $C_{2}$ is a non-dimensional number representing weight dependence of consumption (Table 6$), f\left(\bar{Z}_{i}\right)$ is the total amount of micro- or mesozooplankton consumed in the euphotic layer (Eq. 5b,c), and $f(T)$ is the temperature limitation function of the euphotic zone (Eq. 5d).

Defining the euphotic layer average biomass density $\left(\bar{Z}_{i}\right)$ of mesozooplakton $(i=1)$ or microzooplankton $(i=2)$ as

$$
\overline{\mathrm{Z}}_{i}=\frac{h_{1} \mathrm{Z}_{i, k=1}+h_{2} \mathrm{Z}_{i, k=2}}{h_{1}+h_{2}}
$$

$\bar{Z}_{i}$ is expressed by a sigmoidal function of the form

$$
f\left(\overline{\mathrm{Z}}_{i}\right)=\frac{s_{i} \overline{\mathrm{Z}}_{i}^{2}}{K_{\mathrm{ZA}}^{2}+\sum_{j=1}^{j=2} s_{j} \overline{\mathrm{Z}}_{j}^{2}}
$$

In Eq. (5c), $K_{\mathrm{ZA}}$ is the half saturation constant for individual anchovy feeding on micro- and mesozooplankton (Table 6), and $s_{\mathrm{j}}$ is the food preference coefficient of anchovy for either of them (Table 3). As stated above, anchovy feed only on microzooplankton within the mixed layer until the metamorphosing stage $(<2.5 \mathrm{~cm})$.

The temperature limitation function in the euphotic zone, $f(T)$, is defined by the weighted sum of its contributions for the mixed and sub-thermocline layers, $f_{k}\left(T_{k}\right)$, relative to the thickness of the euphotic layer:

$$
f(T)=\sum_{k=1}^{2} \frac{h_{k}}{h_{1}+h_{2}} f_{k}\left(T_{k}\right) \text { and } f_{k}\left(T_{k}\right)=Q_{10 Z}^{\left(T_{k}-T_{\max }\right) / T_{\text {Zref }}}
$$

with $Q_{10 \mathrm{Z}}=2.2$ and $T_{\mathrm{Zref}}=13^{\circ} \mathrm{C}$ (Table 4 ). This scaling ensures that $f(T)$ does not exceed unity. The temperature control in the mixed layer, $f_{1}\left(T_{1}\right)$, is equal to unity (i.e. optimal) at the maximum mixed layer temperature 
Table 7. Range of control parameters examined for simulation of the transition events TR1, TR2, and TR3. fyr ${ }^{-1}$ : fishing year, defined by the product of daily fishing pressure rate with $165 \mathrm{~d}$ of fishing during $1 \mathrm{yr}$

\begin{tabular}{|llcccc|}
\hline Parameter & Definition & Unit & TR1 & TR2 & TR3 \\
\hline$N_{\mathrm{c}}$ & $\begin{array}{l}\text { Subsurface layer nitrate } \\
\text { concentration }\end{array}$ & $\mathrm{mmol} \mathrm{m}^{-3}$ & $<2.0$ & $2.0-3.5$ & $3.5-10.0$ \\
$\kappa_{\mathrm{Z} 3} \times 10^{-3}$ & $\begin{array}{l}\text { Lateral gelatinous transport } \\
\text { rate from near-shore regions }\end{array}$ & $\mathrm{d}^{-1}$ & 0.0 & $0.5-1.0$ & $1.0-3.0$ \\
$m_{1} \times 10^{-4}$ & $\begin{array}{l}\text { Predation rate by piscivores } \\
m_{\mathrm{f}}\end{array}$ & $\mathrm{m}^{3} \mathrm{~d}^{-1}$ & $1.0-10.0$ & 2.0 & $2.0-3.0$ \\
$\mathrm{fyr}^{-1}$ & 0.3 & 0.3 & $0.5-1.5$ \\
\hline
\end{tabular}

of $25^{\circ} \mathrm{C}$. It never becomes sub-optimal at higher temperatures because the mixed layer temperature does not exceed $25^{\circ} \mathrm{C}$ either in the model or under natural conditions in the Black Sea. The functional form of temperature therefore does not incorporate a decrease at higher temperatures as modeled in other regions like the Chesapeake Bay, USA (Rose et al. 1999). On the other hand, the temperature control in the subthermocline layer, $f_{2}\left(T_{2}\right)$, always remains sub-optimal because of the year-round low temperature of $\sim 7^{\circ} \mathrm{C}$. The overall temperature limitation function of the euphotic zone (Eq. 5d) is therefore always less than unity, even in the warmest summer months, and reduces weight growth efficiency of anchovy.

Respiration involves the sum of routine and active metabolic losses, expressed by Luo \& Brandt (1993) as

$$
R_{\mathrm{A}}=r_{1} \times W_{\mathrm{A}}^{-r_{2}} \times f(T) \times \mathrm{A}_{F}
$$

where $r_{1}\left(\mathrm{mg} \mathrm{C} \mathrm{d}^{-1}\right)$ denotes the maximum rate of routine respiration at optimal temperature (Table 6), $r_{2}$ is the exponent of weight dependence of respiration (Table 6$), f(T)$ is the overall temperature limitation function for the euphotic zone (Eq. 5d), and $\mathrm{A}_{F}$ is a constant anchovy activity factor (Table 5).

The length of any cohort (including adults) is estimated by the relationship $L_{\mathrm{A}}=b_{1} W_{\mathrm{A}}{ }^{b 2}$ with $b_{1}$ and $b_{2}$ being constant coefficients obtained from the observed length (cm)-wet weight (gww) data (Table 5). The weight $W_{\mathrm{A}}$ (in $\mathrm{mgC}$ ) is converted to wet weight using the conversion $1 \mathrm{gC}=9 \mathrm{gww}$. The length and wet weight estimations are useful for calibration and validation of the model, but they do not take part in the model dynamics.

Coupling of anchovy and LTL models. Following Eq. (5a), the daily total consumption rate of mesozooplankton $(i=1)$ and microzooplankton $(i=2)$ by the entire anchovy population in the euphotic layer (i.e. $\tilde{C}_{\mathrm{A}}^{\mathrm{Zi}}$ in Eq. 1b,c,e) is expressed by

$$
\tilde{C}_{\mathrm{A}}^{\mathrm{Zi}}=C N_{\mathrm{r}} \times\left[\sum_{j=1}^{90} C_{1} W_{j}^{-C_{2}} \times\left(W_{j} X_{j}\right)+\sum_{j=1}^{3} C_{1} W_{j}^{-C_{2}} \times\left(W_{j} X_{j}\right)\right] \times f(T) \times f\left(\overline{\mathrm{Z}}_{i}\right)
$$

where the terms within the square brackets combine the sum of individual contributions of all 90 cohorts of the age- 0 class (the first summation) and of the age-1, 2, and 3 classes (the second summation); the coefficient $C N_{\mathrm{r}}=0.01$ converts the consumption rate from $\mathrm{mgC} \mathrm{m} \mathrm{m}^{-3} \mathrm{~d}^{-1}$ to $\mathrm{mmol} \mathrm{N} \mathrm{m}^{-3} \mathrm{~d}^{-1}$ by assuming $100 \mathrm{mgC}=$ $1 \mathrm{mmol} \mathrm{N}$. Eq. (7a) acts like a sink term in Eq. $(1 b, c)$ and a source term in Eq. (1e). It is partitioned among the mixed and the sub-thermocline layers of the LTL model according to the relative food availability of the layers:

$\tilde{C}_{\mathrm{A}, k}^{\mathrm{Zi}}=\tilde{C}_{\mathrm{A}}^{\mathrm{Zi}} \times\left[\frac{h_{k} \mathrm{Z}_{i, k}}{h_{1} \mathrm{Z}_{i, 1}+h_{2} \mathrm{Z}_{i, 2}}\right]$

The second coupling between the HTL and LTL models arises from the predation of gelatinous carnivores (the double underlined terms in Eq. 1c,e) on anchovy eggs and larvae. Incorporating all eggs and larval anchovy $(<2.5 \mathrm{~cm})$ biomass losses from all cohorts of the age- 0 class in the mixed layer $(k=1)$, we write

$$
\tilde{G}_{\mathrm{Z} 3, k=1}^{\mathrm{A}}=C N_{r} \times r_{\mathrm{Z} 3}^{\mathrm{A}} \times \mathrm{Z}_{3, k=1} \times \sum_{i=1}^{90}\left(X_{i} W_{i}\right) \quad \text { if } L<2.5 \mathrm{~cm}
$$

No coupling between anchovy and gelatinous zooplankton exists for the second layer $\left(\tilde{G}_{Z 3, k=2}^{\mathrm{A}}=0\right)$ because of its unfavorable temperature conditions for the survival of anchovy eggs and larvae.

Implementation of the coupled model. Specification of LTL model parameters: The specification of the LTL model parameter values (Tables 1-4) benefits from earlier LTL food web modeling studies (e.g. Oguz et al. 2001, Oguz \& Merico 2006). The model assigns the climatological-mean environmental conditions of photosynthetically available radiation (PAR) and temperature in the layers (Eqs. A3-A5). For computational convenience, we assumed that (1) the euphotic zone has a constant thickness of $50 \mathrm{~m}$. (2) The mixed layer never deepens below the euphotic zone; thus the 2-layer structure of the euphotic zone is maintained throughout the year. In reality, the mixed layer may deepen up to 60-70 $\mathrm{m}$ under occasional strong mixing conditions. (3) The mixed layer depth $\left(h_{1}\right)$ varies linearly during the spring (from 10 March to the end of June) and autumn (October to December) transition periods between its shallowest position (15 $\mathrm{m}$ ) in summer and deepest position (45 m) in winter. (4) When $h_{1}$ $=45 \mathrm{~m}$ (January-February), both layers are allowed to entrain nutrients from the source layer; otherwise the entrainment proceeds only between the first and second layers.

The entrainment rate, $w_{\mathrm{e}}\left(\mathrm{d}^{-1}\right)$, is specified diagnostically by the relationship $w_{\mathrm{e}}=\left(\delta h_{1} / \delta t\right) / h_{\mathrm{s}}$ during the 
deepening phase of the mixed layer, but it is set to 0 during its shallowing phase $h_{\mathrm{s}}$ is a depth scale $(=10 \mathrm{~m})$ to express $w_{\mathrm{e}}$ in $\mathrm{d}^{-1}$. It increases linearly during the deepening phase of the mixed layer from 0 at the beginning of October to its maximum value $0.04 \mathrm{~d}^{-1}$ at the beginning of January. The mixed layer then remains constant at $h_{1}=45 \mathrm{~m}$ until 10 March before returning to 0 . The mixed layer and entrainment variations set were based on preliminary experiments with mixed layer dynamics embedded into the model (Oguz et al. 2001). Nitrate is allowed to diffuse between the layers at a constant rate of $v_{N \mathrm{C}}=0.01 \mathrm{~d}^{-1}$ throughout the year, which corresponds to one-fourth of the maximum entrainment rate in winter. The value of the source layer $N_{\mathrm{c}}$ varies, depending on the particular phase of eutrophication.

The mixed layer temperature follows an increasing trend from its lowest value of $7.0^{\circ} \mathrm{C}$ at the end of February to a maximum value of $25^{\circ} \mathrm{C}$ in July-August. By the end of August, it switches to a decreasing trend over the autumn-winter cooling period of surface waters. The temperature limitation function of the mixed layer (Eq. A5) attains a value of 1 (i.e. no limitation) at $25^{\circ} \mathrm{C}$, but limits plankton and anchovy growth as temperature decreases. Temperature of the subthermocline layer is set to $7.0^{\circ} \mathrm{C}$ throughout the year to incorporate the water mass structure of the permanently cold intermediate layer.

PAR illuminates the deeper part of the euphotic zone less efficiently during the deepening phase of the mixed layer. The mixed layer light limitation function (Eq. A3) decreases to ca. 0.1 during December to February and imposes an additional strong control on phytoplankton growth. As for the temperature limitation, low winter PAR reduces phytoplankton production in the second layer to ca. $50 \%$ of that in the mixed layer.

The model food web assigns 2 major trophic pathways according to the diet composition matrix given in Table 3. The first pathway links carbon fixed by large phytoplankton cells to mesozooplankton and then anchovy. This classical food chain is modeled by assigning diatoms and dinoflagellates to constitute $40 \%$ and $30 \%$ of the mesozooplankton diet, respectively, and mesozooplankton (mostly large copepods and cladocerans) to form $60 \%$ of the anchovy diet. The second pathway extends from small phytoplankton to microzooplankton and gelatinous carnivores. Small phytoplankton constitutes $60 \%$ of the microzooplankton diet; the rest of their diet is equally supplied by smaller cell size diatoms and dinoflagellates. The microzooplankton group itself forms $60 \%$ of the gelatinous diet. The remaining $40 \%$ represent contributions of small size mesozooplankton, juveniles, and nauplii of copepods and cladocerans. Mesozooplankton con- sumption of microzooplankton and gelatinous feeding on anchovy eggs and larvae further links these 2 trophic pathways of the food web.

The growth rate of the gelatinous group $\left(r_{\mathrm{Z} 3}\right.$ in Eq. A7) varies over the year in order to mimic its dependence on temperature and life cycle characteristics. It retains a maximum value of $0.05 \mathrm{~d}^{-1}$ during spring and summer seasons when maximum reproduction takes place and the population is dominated by early life stages with a higher growth rate (Shushkina et al. 1998). It decreases gradually in late autumn and winter to $25 \%$ of its maximum value as the population is formed only by adults and water temperature decreases to around $7^{\circ} \mathrm{C}$.

Specification of anchovy model parameters: The anchovy model comprises 15 parameters. Some of them were specified using available data from the Black Sea and other regions, and the remaining ones were assigned by trial and error adjustment until we achieved a reasonable fit between the ranges of predicted and observed eggs and larvae populations, and mean lengths and weights-at-age for larval and adult stages. Parameters $b_{1}$ and $b_{2}$ of the length-weight relationship (Table 5) were based on the averages of their estimates given by Samsun et al. (2006). Among other parameters listed in Table 5, the egg size and weight were set to $1.8 \mathrm{~mm}$ and $0.23 \mathrm{mg}$ wet weight, to equal approximately $0.02 \mathrm{mgC}$ (Lisovenko \& Andrianov 1996). The spawning efficiency $(S)$ was assigned a moderate value of 0.22 within its observed range of 0.15 to 0.35 (Satilmis et al. 2003, Somarakis 2004). The daily anchovy body weight loss rate $\left(E_{\mathrm{g}}\right)$ for reproduction was assumed to be $0.10 \mathrm{~d}^{-1}$, which was consistent with the general range of 0.05 to $0.10 \mathrm{~d}^{-1}$ reported by Somarakis et al. (2004). The choice of $E_{\mathrm{g}}^{\lambda} S$ in Eq. (2) is less critical than basal mortality rates of egg and yolk-sac larval stages (Table 6), which govern more predominantly surviving larvae and post-larval populations. The utilization efficiency parameter, $\varepsilon_{\mathrm{A}}$, was set to 0.5 (Table 5). It does not vary with body size and feeding conditions and therefore does not constrain the weight growth under high food conditions (Rose et al. 1999, Peck \& Daewel 2007).

The basal mortality rate $\left(m_{\mathrm{b}}\right)$ was the most difficult parameter to specify, especially for pre-recruitment stages. On the basis of various data sets (Gordina et al. 1998, Kideys et al. 1999, Sorokin 2002, Satilmis et al. 2003) and optimization experiments, we assigned $65 \%$ population loss $\mathrm{d}^{-1}$ for eggs and yolk-sac larvae, $30 \%$ for early larvae, and $10 \%$ for late larvae. This setting roughly corresponds to the basal mortality rate of $1.0 \mathrm{~d}^{-1}$ for the eggs and yolk-sac larval phases, $0.3 \mathrm{~d}^{-1}$ for early larvae, and $0.1 \mathrm{~d}^{-1}$ for late larvae (Table 6). These values are similar to those expressed as a function of length by Rose et al. (1999) and slightly higher than those given by Sorokin (2002). We further as- 
signed $m_{\mathrm{b}}$ as $0.02 \mathrm{~d}^{-1}$ for juveniles and $0.007 \mathrm{~d}^{-1}$ for YoY (Table 6). The adult rate of $0.001 \mathrm{~d}^{-1}$ was defined on the basis of various data sets compiled by Samsun et al. (2006). The fish predation mortality rate, $m_{1}$, is one of the control parameters in the model that varied between 0.0001 and $0.0010 \mathrm{~m}^{3} \mathrm{~d}^{-1}$ (Table 7) in order to identify its most appropriate values for different anchovy stock transition periods.

The consumption and respiration parameters are stage-dependent and mostly follow those given by Monteiro (2000). The nondimensional parameter $c_{2}$ varies from 0.27 for early larvae to 0.32 for YoY and adult classes (Table 6). The maximum food consumption rate $c_{1}$ decreased from its greatest value of $1.23 \mathrm{mgC} \mathrm{d}^{-1}$ for early larvae to $0.33 \mathrm{mgC} \mathrm{d}^{-1}$ for adults (Table 6). The value of $K_{\mathrm{ZA}}=135 \mathrm{mgC} \mathrm{m}^{-3}$ resulted in more efficient weight growth of the early life stages when assuming $225 \mathrm{mgC} \mathrm{m}^{-3}$ for the adult age classes (Table 6). As shown in the following sections, increasing values of $c_{1}$ and $K_{\mathrm{ZA}}$ have contrasting effects on anchovy weight growth and need to be adjusted simultaneously. $r_{1}$ increased from $0.022 \mathrm{mgC} \mathrm{d}^{-1}$ for early larvae to $0.028 \mathrm{mgC} \mathrm{d}^{-1}$ for YoY and adults (Table 6). $r_{2}$ was set to 0.34 for all age classes.

Fishing mortality $\left(m_{\mathrm{f}}\right)$ was imposed on recruits and adults greater than $7 \mathrm{~cm}$ during the fishing period, which lasts for $165 \mathrm{~d}$ from 1 October to 15 March every year. Typically, this period accounts for more than $80 \%$ of the total annual landings (Prodanov et al. 1997). The fishing mortality rate was defined per day $\left(\mathrm{d}^{-1}\right)$, but is expressed hereafter as per fishing year $\left(\mathrm{fyr}^{-1}\right)$, which equals the product of the daily rate with the $165 \mathrm{~d}$ fishing period. This value corresponds to $46 \%$ of the value customarily reported as per year $\left(\mathrm{yr}^{-1}\right)$. The range of $m_{\mathrm{f}}$ values for each stock transition event is given in Table 7 .

Time integration and attainment of steady state: The anchovy and LTL model equations were solved simultaneously by the Euler time stepping algorithm with a $1 \mathrm{~h}$ time step and repeated environmental conditions over each year. The annual cycle commences with the beginning of the anchovy spawning season on calendar day 151 (1 June). The model was initialized with small values for nitrate concentration, phytoplankton and zooplankton biomass densities, 1 egg $\mathrm{m}^{-3} \mathrm{~d}^{-1}$ during the spawning period, and 0.1 adult ind. $\mathrm{m}^{-3}$ and their typical observed weights. Irrespective of the initial setting of the values of state variables, the time integration of the equations established a particular steady-state of the yearly food web structure with repeating seasonal cycles of each state variable in response to the parameter setting, external forcing factors and the subsequent balance between nitrate input from the source layer and the export flux from the euphotic zone. The steady-state solutions arose due to the absence of interannual variability in the externally specified parameters and forcing functions. The spinup time took approximately $5 \mathrm{yr}$ for the anchovy weight growth and the LTL model, and $10 \mathrm{yr}$ for the anchovy population growth model. However, the time integration always spanned a total of $30 \mathrm{yr}$ (assuming $360 \mathrm{~d} \mathrm{yr}^{-1}$ ) in all simulations. The simulation results presented in the subsequent sections are based on the daily-averaged values of the properties from the 30th year.

\section{DESIGN OF MODEL SIMULATIONS}

Synopsis of key assumptions and simplifications in the anchovy model. Major simplifications and assumptions used in the coupled model that set up physiology, growth, and survival characteristics of the anchovy population are briefly summarized here as a prelude to the simulation experiments described in the following section. They are listed as follows: (1) the LTL model is driven by climatological mean monthly forcing of temperature, light, mixed layer depth, and entrainment velocity. The LTL model therefore does not include any interannual variability. However, annual zooplankton and gelatinous biomass may vary during different transition periods, depending on the intensity of bottom-up and top-down controls. (2) Spawning always takes place under the same (climatological mean) summer temperature conditions. For given values of constant spawning efficiency and spawning rate, its year-to-year variations therefore depend only on variations in body weight and population size of adult females. (3) The basal mortality rate is kept unchanged throughout the simulation period of rapid stock changes, but the overall natural mortality (Eq. 3b) varies due to the changes in predation mortalities during different phases of anchovy stock changes. (4) The bioenergetics model does not incorporate a seasonally varying energy density ratio of zooplankton and anchovy. A constant energy density ratio value is absorbed into the maximum consumption and respiration rates. (5) Differential zooplankton feeding of different anchovy life stages is not incorporated into the weight growth formulation, because such details are not available from observations for the 1970s and 1980s. This simplification likely leads to more efficient food consumption and thus less starvation than may take place in nature. (6) The predation mortality caused by large pelagics is not explicitly modeled. Instead, it is parameterized by a density-dependent mortality function. The fish predator mortality therefore changes both seasonally and during different stock transition periods depending on anchovy populations. (7) Large pelagics predate all anchovy size classes at the same rate, 
although their predation rate may in reality be higher for larvae and juveniles. (8) Intra-specific competition and limitation of weight growth by population size are not incorporated. (9) Inter-specific interactions with other fish species (e.g. sprat, sardine) that share the same trophic level with anchovy are not included. (10) The anchovy consumption of zooplankton does not incorporate the foraging parameterization (e.g. Rose et al. 1999). (11) All cohorts of the age-0 class are merged into a single cohort of age- 1 class at the beginning of the new spawning period instead of tracking each cohort independently up to the end of the fourth year. This approach implies that the age-1 and older age class stocks are estimated by the product of average weight of all cohorts with the total population of cohorts. The validity of this simplification was assessed by comparing the stock of the age- 0 class prior to the beginning of the following spawning season. This approach overestimated the total recruitment stock by between $10 \%$ and $15 \%$ for different simulations with respect to the alternative estimate based on the total biomass of all cohorts. It allows a better comparison of the model-derived stock estimates with the virtual population analysis (VPA) estimates of Prodanov et al. (1997) computed by the multiplication of year class abundances with their respective observed mean weights.

Outline of the simulation experiments. The simulations presented in the subsequent sections are classified in 2 groups. The first group involves sensitivity of the anchovy model to the changes in some critical parameters that are kept fixed for all simulations and therefore do not directly control the hypothesized anchovy and gelatinous biomass transitions. The second group examines sensitivity of model dynamics to 4 specific parameters that likely governed anchovy and gelatinous biomass changes during different phases of the ecosystem. They are as follows: (1) $N_{\mathrm{c}}$ the subsurface nitrate concentration (a measure of bottom-up control due to nutrient enrichment); (2) $\kappa_{\mathrm{Z} 3}$, the external source of gelatinous biomass transported into the area from near-coastal regions where they reproduce and grow (a measure of top-down gelatinous control), (3) $m_{1}$, the piscivorous fish predation pressure rate (a measure of top-down fish predator control), and (4) $m_{\mathrm{f}}$, the anchovy fishing mortality rate (a measure of top-down fishing pressure control). Their values used for different experiments are listed in Table 8. Observed features of each transition event that further constrain their choices are described below.

Transition TR1: The lack of strong climate-induced variations, low nutrient content within the water column and associated weak bottom-up control, low anchovy stock $(\sim 300 \mathrm{kt})$ and catch $(<100 \mathrm{kt})$, and negligible gelatinous biomass characterized the ecosystem prior to 1970 (Oguz \& Gilbert 2007). The most conspicuous observed feature of TR1 was the considerable decrease of piscivorous predation pressure on small pelagics due to depletion first of dolphins, large pelagics, and demersals, and then horse mackerel towards the end of the 1960s, and finally bonito and bluefish during the early 1970s (see Fig. 43 in Sorokin 2002). The changes in the piscivore predation pressure are incorporated in the model by varying $m_{1}$ between its 2 extreme values of 0.001 and $0.0001 \mathrm{~m}^{3} \mathrm{~d}^{-1}$ at an increment of $0.0001 \mathrm{~m}^{3} \mathrm{~d}^{-1}$ (Table 7). Its relatively high values identify the low anchovy-high predator stock regime prior to TR1, while its low values correspond to the opposite high anchovy-low predator stock regime of the post-transition state. The pre- and post-transition states are further characterized by low subsurface nitrate source concentrations $\left(N_{\mathrm{c}}<2.0 \mathrm{mmol} \mathrm{m}^{-3}\right)$, a

Table 8. Simulations, corresponding phases of the ecosystem, and the parameter values used in different simulation experiments for different phases of the ecosystem. Variable: parameter values not set. SR: Low Stock Regime, MSR: Medium Stock Regime, HSR: High Stock Regime, TDS: time-dependent simulation

\begin{tabular}{|c|c|c|c|c|c|}
\hline Simulations & $\begin{array}{l}\text { Ecosystem } \\
\text { phase }\end{array}$ & $\begin{array}{c}N_{\mathrm{c}} \\
\left(\mathrm{mmol} \mathrm{m}^{-3}\right)\end{array}$ & $\begin{array}{c}C_{1} \\
\left(10^{-4} \mathrm{~m}^{3} \mathrm{~d}^{-1}\right)\end{array}$ & $\begin{array}{c}\kappa_{\mathrm{Z} 3} \\
\left(10^{-3} \mathrm{~d}^{-1}\right)\end{array}$ & $\begin{array}{c}m_{\mathrm{f}} \\
\left(\mathrm{fyr}^{-1}\right)\end{array}$ \\
\hline LSR1 & Before TR1 & 1.5 & Variable & 0 & 0.3 \\
\hline LSR2 & $\begin{array}{l}\text { Transition TR1 } \\
\text { (before TR2) }\end{array}$ & 1.8 & Variable & 0. & 0.3 \\
\hline MSR1 & Transition TR2 & Variable & 2.0 & 0. & 0.3 \\
\hline MSR2 & & Variable & 2.0 & 0.5 & 0.3 \\
\hline MSR3 & & Variable & 2.0 & 1.0 & 0.3 \\
\hline HSR11 (ea & $\begin{array}{l}\text { After TR2 } \\
\text { ly and mid-1980s) }\end{array}$ & 3.5 & 2.0 & 0.5 & 0.6 \\
\hline HSR12 & & 4.0 & 2.0 & 1.0 & 0.5 \\
\hline HSR5 (ov & $\begin{array}{l}\text { Transition TR3 } \\
\text { erfishing scenario) }\end{array}$ & 3.0 & 2.0 & 0.5 & Variable \\
\hline HSR6 & & 3.0 & 2.0 & 1.5 & Variable \\
\hline HSR7 & & 3.0 & 2.0 & 2.5 & Variable \\
\hline HSR8 & & 3.0 & 3.0 & 1.5 & Variable \\
\hline HSR9 & & 3.0 & 2.0 & Variable & 0.3 \\
\hline HSR10 & & 3.0 & 2.0 & Variable & 0.8 \\
\hline $\begin{array}{l}\text { HSR4 } \\
\text { (over- }\end{array}$ & $\begin{array}{l}\text { Transition TR3 } \\
\text { enrichment scenario) }\end{array}$ & Variable & 2.0 & 1.0 & 0.8 \\
\hline $\begin{array}{l}\text { TDS1 } \\
\begin{aligned} \text { (time- } \\
\text { compr } \\
\text { over- } \epsilon\end{aligned}\end{array}$ & $\begin{array}{l}\text { Transition TR3 } \\
\text { dependent simulation } \\
\text { ising overfishing and } \\
\text { nrichment scenarios) }\end{array}$ & Variable & 2.5 & 0.8 & Variable \\
\hline
\end{tabular}


low fishing mortality rate $\left(m_{\mathrm{f}} \leq 0.3 \mathrm{fyr}^{-1}\right)$ and a negligible supply of young Aurelia from near-coastal regions $\left(\kappa_{\mathrm{Z} 3}=0\right)$.

Transition TR2: This transition coincides with the period of intensifying eutrophication and deteriorating ecological state of the Black Sea (Fig. 2). Aurelia biomass of $\sim 1.0 \mathrm{gC} \mathrm{m}^{-2}$ was recorded in April-May and September-October in different regions of the basin (Shushkina \& Musayeva 1983, Sorokin 2002). The exploitable anchovy stock and catch increased to 1300$1400 \mathrm{kt}$ and 450-500 kt, respectively (Fig. 1). The fishing pressure was still low (Ivanov \& Panayotova 2001), and the predation mortality caused by piscivores was already reduced to its low values. Thus, the transition TR2 appears to be controlled primarily by the changes in $N_{\mathrm{C}}$ and $\kappa_{\mathrm{Z} 3}$. This hypothesis was tested by the simulations in which $N_{\mathrm{c}}$ covered the range between $1.0 \mathrm{mmol} \mathrm{m}^{-3}$ and $3.5 \mathrm{mmol} \mathrm{m}^{-3}$ for different choices of $\kappa_{\mathrm{Z} 3}$ (Table 7).

Transition TR3: According to Fig. 1, the high anchovy stock regime over $1000 \mathrm{kt}$ persisted up to 1988 and then declined markedly to $350 \mathrm{kt}$ around 19891990 with a concomitant increase of gelatinous biomass up to $3.0 \mathrm{gC} \mathrm{m}^{-2}$ during their spring and latesummer reproduction periods (Fig. 2). One of the critical factors that controlled the size of the anchovy stock was the change in fishing pressure due particularly to the increasing Turkish purse seine fleet capacity (Bilgin 2006). Some recovery of medium and demersal stocks (Sorokin 2002, Oguz 2007) and thus their somewhat higher predation pressure on anchovy compared to the early 1980s, as well as further enrichment of the biologically productive surface layer (Fig. 2), may have been other factors contributing to anchovy stock changes during the late 1980s.

With regard to enrichment, the model considers that nitrate accumulated in the upper chemocline zone during the 1980s was more efficiently supplied into the euphotic zone by stronger and deeper turbulent mixing in the water column that apparently took place between 1985 and 1987, following the switch of the North Atlantic Oscillation index from a strongly negative to a strongly positive mode (Oguz et al. 2006). The impact of severe winter conditions on the water column physical structure for this period was evident by the deeper and cooler winter mixed layer and the cooler summer subthermocline layer (Fig. 1a,b in Oguz et al. 2006).

\section{RESULTS}

\section{Sensitivity experiments for the anchovy model}

The basal mortality $\left(m_{\mathrm{b}}\right)$, the maximum consumption rate $\left(c_{1}\right)$, and the half saturation constant of anchovy feeding on zooplankton $\left(K_{\mathrm{ZA}}\right)$ were the most critical parameters controlling the anchovy population and weight growth dynamics. We found that $\pm 10 \%$ changes in $m_{\mathrm{b}}$ with respect to its optimized values at different life stages (Table 6) introduced considerable differences in the age-0 class population (Fig. 4a). The total population varied between 0.4 and 0.6 ind. $\mathrm{m}^{-3}$ during the first half of June (early phase of the spawing season with limited egg population density) when the mixed layer temperature was below $20^{\circ} \mathrm{C}$. As soon as it exceeded $20^{\circ} \mathrm{C}$, active spawing started, and a population size of between 1.5 and 4.4 ind. $\mathrm{m}^{-3}$ persisted until the end of the spawning period (Day 90). Populations rapidly decreased by more than 1 order of magnitude to a range of 0.10 to 0.01 ind. $\mathrm{m}^{-3}$ in September to November (Day 91 to 150) due to high mortality rates during the early life stages of anchovy. Thereafter, the rate of population decrease weakened gradually for the recruits, but change of 1 order of magnitude (between 0.030 and 0.002 ind $\mathrm{m}^{-3}$ ) persisted toward the end of the year around a mean population of 0.010 ind. $\mathrm{m}^{-3}$ for the optimum value of the basal mortality rate. The increase in $m_{b}$ apparently introduced a higher population difference with respect to

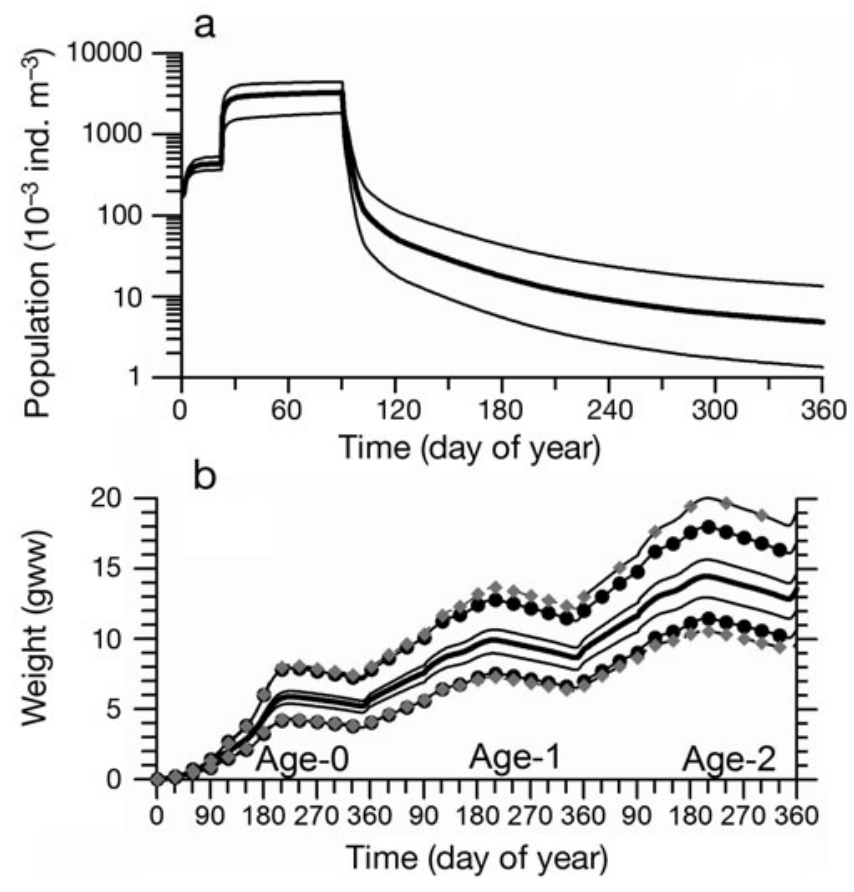

Fig. 4. Engraulis encrasicolus ponticus. (a) Daily-mean population of all cohorts of the age- 0 class and (b) daily-mean weights (gww) of the age- 0 , age- 1 , and age- 2 classes for: the 'moderate stock regime' simulation (MSR2 in Table 10) (thick line) and simulations with a $\pm 10 \%$ change in the basal mortality rate (thin lines). Additional simulations show $\pm 10 \%$ changes in the maximum consumption rate $(\bullet)$ and the half saturation constant of zooplankton consumption ( $\diamond$ ). Day 0 refers to the start of the spawning season on 1 June 
the same amount of decrease. This implies complex nonlinear feedback mechanisms controlling anchovy population dynamics.

Population changes due to variations in $m_{\mathrm{b}}$ also affected the weight growth up to $1.5 \mathrm{gww}$ in older age classes (Fig. 4 b). Similarly, $\pm 10 \%$ changes in either $c_{1}$ or $K_{\mathrm{ZA}}$ resulted in a weight difference of \pm 1.5 to $2.0 \mathrm{gww}$ in the recruits that further increased up to $\sim 5.0 \mathrm{gww}$ for the older age classes (Fig. 4b). A notable feature of all simulations was the linear weight increase during the first $210 \mathrm{~d}$ (summer to mid-winter) and the slowed growth and the eventual weight loss during late winter and early spring (Day 210 to 330) due to food limitation and low water temperatures $\left(<10^{\circ} \mathrm{C}\right)$. Positive weight growth started only after Day 330 (beginning of May) with the commencement of warming, enhanced plankton production, and the active zooplankton feeding period.

\section{Corroboration of the anchovy model}

The simulated anchovy egg population, length, and weight changes for all age-classes agreed with their observed ranges. The daily average egg population (i.e. total eggs per $90 \mathrm{~d}$ spawning period) within the $15 \mathrm{~m}$ mixed layer varied between a minimum of $\sim 20$ eggs $\mathrm{m}^{-2}$ for the pristine state (1960s) and the collapsed state (end of the 1980s), and a maximum of $\sim 100$ eggs $\mathrm{m}^{-2}$ during the intense eutrophication phase prior to the outburst of Mnemiopsis (Table 9). A comparison to historical data was not possible due to the lack of egg and larval surveys within the Black Sea between 1963 and 1986 (Niermann et al. 1994). The available data up to 1963 were limited to the northwestern shelf and the Crimean region (hereafter referred to as NWCR) that was already eutrophic in the 1960s and became hypertrophic in the 1980s. Within the limitations of data availability, the computed egg population for the 1980s can best be compared to the data representative of the 1960s' eutrophic environment of the NWCR, and the 1960s' pristine state with the data from the 1950s preeutrophication environment of the NWCR. This comparison (Table 9) showed the capability of the model to capture the correct magnitude of the egg population under different ecosystem conditions.

The lack of data also hindered a comparison of the daily mean length of larvae of all cohorts with observations. We therefore used the data from other seas representative of different environmental conditions to ensure that our model did not provide any atypical anchovy larval length growth. The linear length increase up to 2.0 to $3.0 \mathrm{~cm}$ within the first $40 \mathrm{~d}$ after hatching deduced for different simulations was within the range of these observations (Fig. 5).

Daily average weight and length variations of postlarvae and adult populations (Fig. 6a,b) obtained from different simulations (Table 10) agreed well with the empirical data from Turkish coastal waters during November to February of 1985 to 2005 (Uckun et al. 2005, Samsun et al. 2006). Both the mean length and weight of anchovy experienced their largest growth up

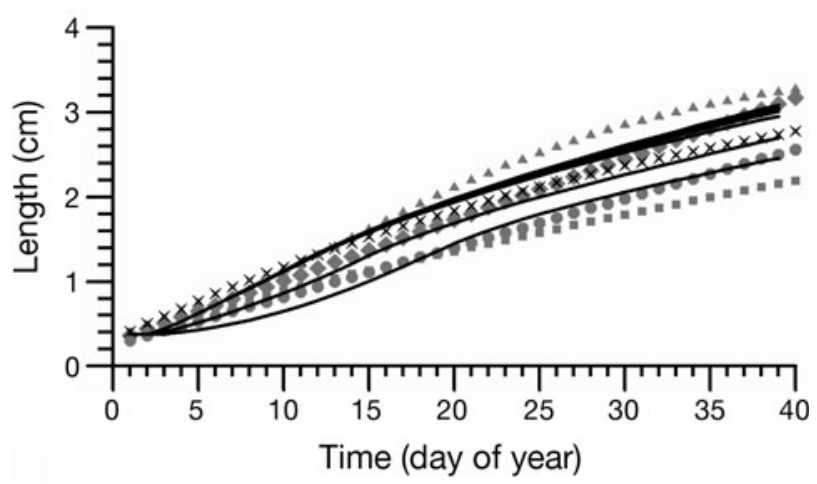

Fig. 5. Engraulis encrasicolus ponticus. Observed and simulated length of larvae over time. The continuous lines correspond to the daily mean length of all cohorts for the simulations listed in Table 10. Symbols refer to the observations reported by $\square$ : Rilling \& Houde (1999), $\Delta$ : Castro \& Cowen (1991), : Dulcic (1997), ×: Chin \& Chen (2001), and ๑: GarciaLafuente et al. (2002)

Table 9. Comparison of computed and observed egg populations during different periods of the Black Sea ecosystem. Values of 4 control parameters are given for each listed simulation. Bold numbers represent specific values of parameters that were assigned as 'variable' in Table 8 for the simulations LSR1, LSR2 and HSR2, HSR4

\begin{tabular}{|c|c|c|c|c|c|c|c|}
\hline \multirow[t]{2}{*}{ Period } & \multirow[t]{2}{*}{ Simulation } & \multicolumn{4}{|c|}{ Input (control) parameters } & \multicolumn{2}{|c|}{ Egg number $\left(\mathrm{m}^{-2}\right)$} \\
\hline & & $\begin{array}{c}N_{\mathrm{c}} \\
\left(\mathrm{mmol} \mathrm{m}^{-3}\right)\end{array}$ & $\begin{array}{c}m_{1} \\
\left(10^{-4} \mathrm{~m}^{3} \mathrm{~d}^{-1}\right)\end{array}$ & $\begin{array}{c}\kappa_{\mathrm{Z3}} \\
\left(10^{-3} \mathrm{~d}^{-1}\right)\end{array}$ & $\begin{array}{c}m_{\mathrm{f}} \\
\left(\mathrm{fyr}^{-1}\right)\end{array}$ & Computed & Observed $^{\mathrm{a}}$ \\
\hline 1960s (before TR1) & LSR1 & 1.5 & 4.0 & 0 & 0.3 & 20 & 23 \\
\hline Mid-1970s (after TR1) & LSR2 & 1.8 & 2.5 & 0 & 0.3 & 44 & 35 \\
\hline Early 1980s (after TR2) & MSR2 & 3.0 & 2.0 & 0.5 & 0.3 & 101 & $190,50,73^{\mathrm{b}}$ \\
\hline 1990 (after TR3) & HSR4 & 6.0 & 2.0 & 1.0 & 0.8 & 32 & $6,8,1$ \\
\hline
\end{tabular}



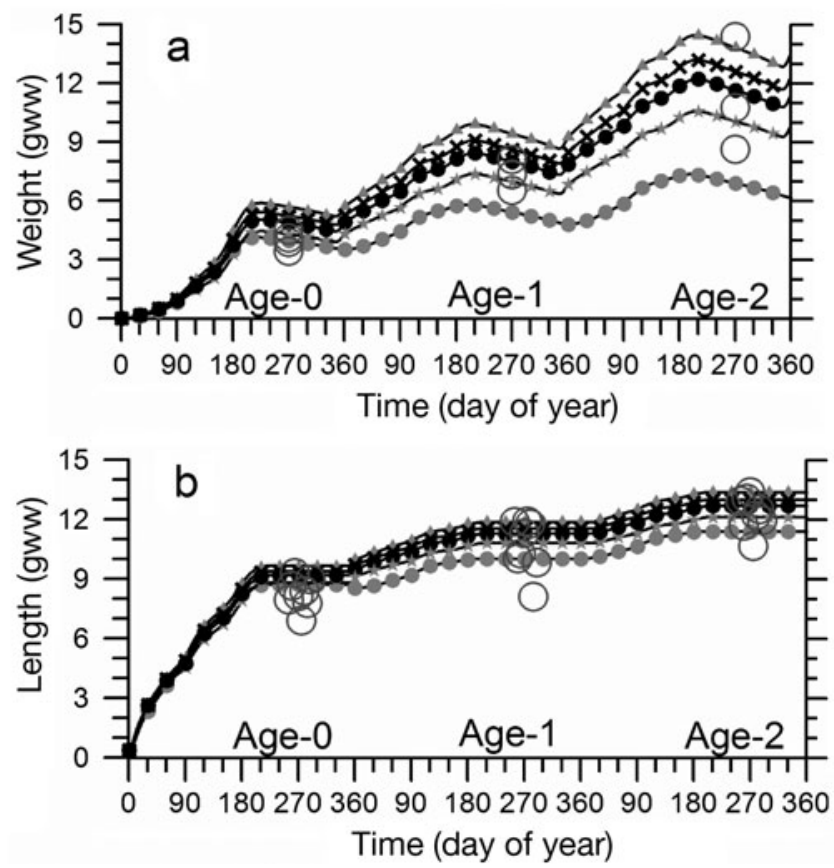

Fig. 6. Engraulis encrasicolus ponticus. (a) Daily-mean weight (gww) and (b) mean length ( $\mathrm{cm}$ ) of age-0, age-1, and age-2 populations for different simulations (case no.) given in Table $10(\bullet: 2, \star: 5 \mathrm{a}, \bullet: 5 \mathrm{~b}, \times: 4 \mathrm{a}, \Delta: 3)$. Large circles superimposed on the simulated results represent the mean weight and length of each age class obtained by measurements performed during the fishing season of different years (Uckun et al. 2005, Samsun et al. 2006). Day 0 refers to the start of the spawning season on 1 June to about $9 \pm 1.0 \mathrm{~cm}$ and $5 \pm 1.0 \mathrm{gww}$ during the first 6 mo. The weight growth ranged between 2 and 4 gww $\mathrm{yr}^{-1}$ and 3 and 5 gww $\mathrm{yr}^{-1}$ for age- 1 and age- 2 classes, respectively, and between 1.5 and $3 \mathrm{~cm} \mathrm{yr}^{-1}$ for the length for both adult age classes. The largest deviation of the simulated weight from observations appeared for age-0 and age-1 year classes of the high stock regime (HSR, in the early 1980s) that represented the conditions of low-to-moderate fishing pressure, high food availability, and relatively low gelatinous pressure (Fig 6a). This may be partly due to the mismatch between the periods of observed and simulated stocks. Over-prediction of the weight growth under high carrying capacity conditions may also have contributed to the difference.

\section{Transition from low to moderate stock regime (TR1)}

The mechanisms causing the changes in anchovy properties before and after the transition TR1 were described by 2 particular simulations (Table 8; Low Stock Regime [LSR] 1 and LSR2). Fig. 7a-c depicts anchovy egg density, stock, and catch versus piscivore predation pressure for $N_{\mathrm{C}}=1.5$ and $1.8 \mathrm{mmol} \mathrm{m}^{-3}$. The simulation LSR1 with $N_{\mathrm{c}}=1.5 \mathrm{mmol} \mathrm{m}^{-3}$ and $m_{1} \geq 0.0004 \mathrm{~m}^{3}$ $\mathrm{d}^{-1}$ represented the LSR with a limited number of total egg density on the order of 100 eggs $\mathrm{m}^{-3}$ over the entire spawning period (Fig. 7a). It roughly corre-

Table 10. Summary of control (input) parameter values that most appropriately defined the anchovy stock, catch, and gelatinous biomass changes (output variables)

\begin{tabular}{|c|c|c|c|c|c|c|c|c|c|c|}
\hline \multirow{2}{*}{$\begin{array}{l}\text { Case } \\
\text { no. }\end{array}$} & \multirow{2}{*}{ Period } & \multirow[t]{2}{*}{ Simulation } & \multicolumn{4}{|c|}{ Input (control) parameters } & \multicolumn{4}{|c|}{ - Output (response) variables } \\
\hline & & & $\begin{array}{c}N_{\mathrm{c}} \\
\left(\mathrm{mmol} \mathrm{m}^{-3}\right)\end{array}$ & $\begin{array}{c}m_{1} \\
\left(10^{-4} \mathrm{~m}^{3} \mathrm{~d}^{-1}\right)\end{array}$ & $\begin{array}{c}\kappa_{\mathrm{Z} 3} \\
\left(10^{-3} \mathrm{~d}^{-1}\right)\end{array}$ & $\begin{array}{c}m_{\mathrm{f}} \\
\left(\mathrm{fyr}^{-1}\right)\end{array}$ & $\begin{array}{l}\text { Total } \\
\text { eggs } \\
\left(\mathrm{m}^{-3}\right)\end{array}$ & $\begin{array}{c}\text { Exploitable } \\
\text { anchovy stock } \\
\left(\mathrm{t} \mathrm{km}^{-2}\right)\end{array}$ & $\begin{array}{l}\text { Anchovy } \\
\text { catch } \\
\left(\mathrm{t} \mathrm{km}^{-2}\right)\end{array}$ & $\begin{array}{c}\text { Gelatinous } \\
\text { biomass } \\
\left(\mathrm{gC} \mathrm{m}^{-2}\right)\end{array}$ \\
\hline 1 & $\begin{array}{c}1960 \mathrm{~s} \\
\text { (before TR1) }\end{array}$ & LSR1 & 1.5 & 4.0 & 0.0 & 0.3 & 122 & 1.98 & 0.48 & 0.1 \\
\hline 2 & $\begin{array}{l}\text { Mid-1970s) } \\
\text { (after TR1) }\end{array}$ & LSR2 & 1.8 & 2.5 & 0.0 & 0.3 & 269 & 5.08 & 1.35 & 0.3 \\
\hline 3 & $\begin{array}{l}\text { Late 1970s } \\
\text { (after TR2) }\end{array}$ & MSR2 & 3.0 & 2.0 & 0.5 & 0.3 & 608 & 9.57 & 3.01 & 0.7 \\
\hline $4 \mathrm{a}$ & $\begin{array}{l}\text { Mid-1980s } \\
\text { (before TR3) }\end{array}$ & HSR11 & 3.5 & 2.0 & 0.5 & 0.6 & 434 & 7.41 & 4.21 & 1.2 \\
\hline $4 \mathrm{~b}$ & $\begin{array}{l}\text { Mid-1980s } \\
\text { (before TR3) }\end{array}$ & HSR12 & 4.0 & 2.0 & 1.0 & 0.5 & 484 & 6.91 & 3.81 & 1.3 \\
\hline $5 a$ & $\begin{array}{c}\text { After TR3 } \\
\text { (overfishing) }\end{array}$ & HSR10 & 3.0 & 2.0 & 2.5 & 0.8 & 176 & 2.94 & 1.88 & 1.2 \\
\hline $5 b$ & $\begin{array}{c}\text { After TR3 } \\
\text { (overfishing) }\end{array}$ & HSR8 & 3.0 & 3.0 & 1.5 & 0.8 & 166 & 2.84 & 1.80 & 1.2 \\
\hline${ }^{5 \mathrm{c}}$ & $\begin{array}{c}\text { After TR3 } \\
\text { ver-enrichmen }\end{array}$ & nt) & 6.0 & 2.0 & 1.0 & 0.8 & 197 & 2.37 & 0.90 & 3.0 \\
\hline
\end{tabular}



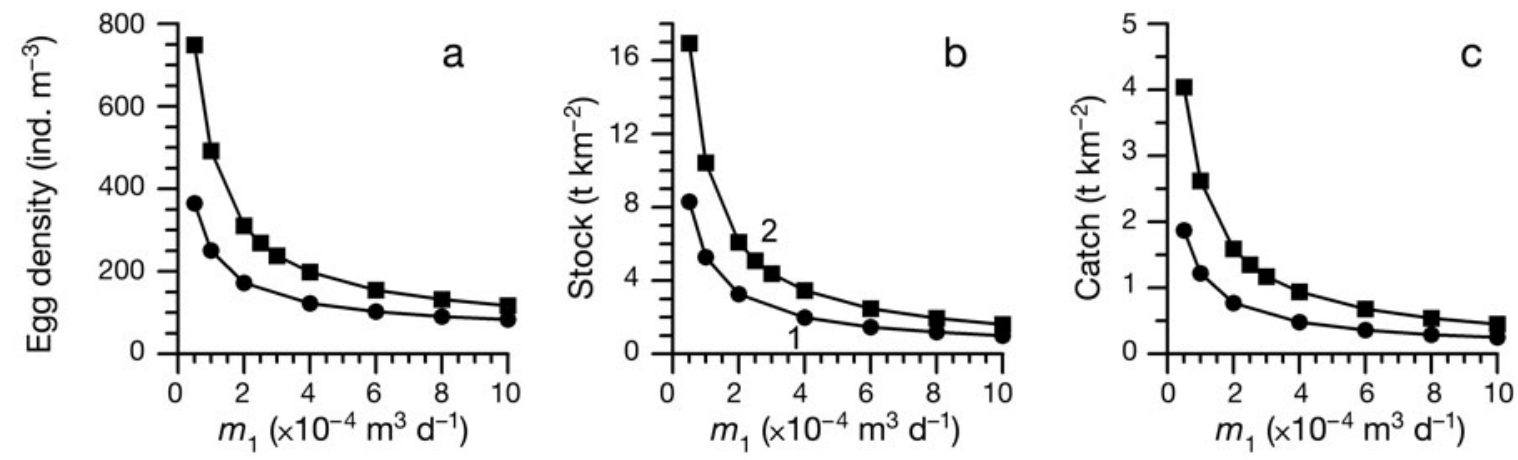

Fig. 7. Engraulis encrasicolus ponticus. Predation mortality $\left(m_{1}\right)$ versus (a) total egg density produced during the entire spawning season (1 June to 31 August), (b) exploitable stock on 1 October with the arrow representing the transition of stock from its pretransition state 1 to post-transition state 2, (c) total catch during the fishing season (1 October to 15 March) for the simulations LSR1 (•) and LSR2 (घ) with the parameter values listed in Table 9

sponded to 1 egg $\mathrm{m}^{-3}$ (or 15 eggs $\mathrm{m}^{-2}$ ) per day, which is in agreement with observations (Table 9). The limited egg production resulted in a relatively low exploitable stock around 1.0 to $2.0 \mathrm{t} \mathrm{km}^{-2}$ (Fig. $7 \mathrm{~b}$ ) and catch of 0.25 to $0.5 \mathrm{t} \mathrm{km}^{-2}$ (Fig. $7 \mathrm{c}$ ). These values may be compared to observations when the total stock and catch data (Fig. 1) are divided by $150000 \mathrm{~km}^{2}$, which amounts to the total surface area of the peripheral zone shallower than $1000 \mathrm{~m}$ (Prodanov et al. 1997) and corresponds roughly to fishing and spawning grounds over the Black Sea (Ivanov \& Beverton 1985). Then, the choice of $m_{1}$ at $\sim 0.0004 \mathrm{~m}^{3} \mathrm{~d}^{-1}$ (Table 10; case no. 1) reproduced well the observed exploitable stock value of $\sim 300 \mathrm{kt}\left(2.0 \mathrm{t} \mathrm{km}^{-2}\right)$ and a catch value of $\sim 75 \mathrm{kt}(0.5 \mathrm{t}$ $\mathrm{km}^{-2}$ ). Similarly, the choices of $N_{\mathrm{c}}=1.8 \mathrm{mmol} \mathrm{m} \mathrm{m}^{-3}$ at $m_{1}$ $=0.00025 \mathrm{~m}^{3} \mathrm{~d}^{-1}$ (Table 10; case no. 2) provided the post-transition state with an observed stock of $\sim 5.0 \mathrm{t}$ $\mathrm{km}^{-2}$ and catch of $\sim 1.5 \mathrm{t} \mathrm{km}^{-2}$.

The latter solution implied that even a minor increase in $N_{\mathrm{c}}$ from its pre-transition value of 1.5 to $1.8 \mathrm{mmol} \mathrm{m}^{-3}$ and a decrease in $m_{1}$ from 0.0004 to $0.00025 \mathrm{~m}^{3} \mathrm{~d}^{-1}$ were sufficient to alter both stock and catch by $100 \%$ due to the relative increase in resource availability and simultaneous decrease in predation loss. Small changes in $N_{\mathrm{c}}$ that accompanied the change in $m_{1}$ may be interpreted as a response of the early eutrophication phase. Even in the absence of any change in $N_{\mathrm{c}}$ a similar stock increase was possible if $m_{1}$ was reduced to $0.00015 \mathrm{~m}^{3} \mathrm{~d}^{-1}$, implying a stronger loss of piscivorous predation control. In the absence of data on changes of $N_{\mathrm{c}}$ and $m_{1}$, it was not possible to assess which choice may more appropriately define the transition process. In the latter case, anchovy stocks increased merely due to the direct effect of predation pressure on population increase and its positive and negative feedbacks (Fig. 8). In the former case (enrichment plus predation loss), both weight and population increase contributed to the stock change.

The lower trophic level responded weakly to a new and different top-down control introduced by the transition. The annual mean total zooplankton biomass decreased from 0.75 to $0.63 \mathrm{gC} \mathrm{m}^{-2}$, and the phytoplankton biomass increased from 2.82 to $2.90 \mathrm{gC} \mathrm{m}^{-2}$. The competitive disadvantage of the gelatinous group feeding on zooplankton relative to anchovy (set by $c_{1}>$ $\left.r_{Z 3}\right)$, together with low availability of anchovy eggs and larvae, deferred gelatinous biomass growth under the conditions of limited zooplankton productivity.

The transition TR1 across the threshold ranges of $m_{1}$ at $\sim 0.00025$ to $0.0004 \mathrm{~m}^{3} \mathrm{~d}^{-1}$ and $N_{\mathrm{c}}$ at $\sim 1.5$ to $1.8 \mathrm{mmol} \mathrm{m}^{-3}$ was supported by concurrent positive and negative

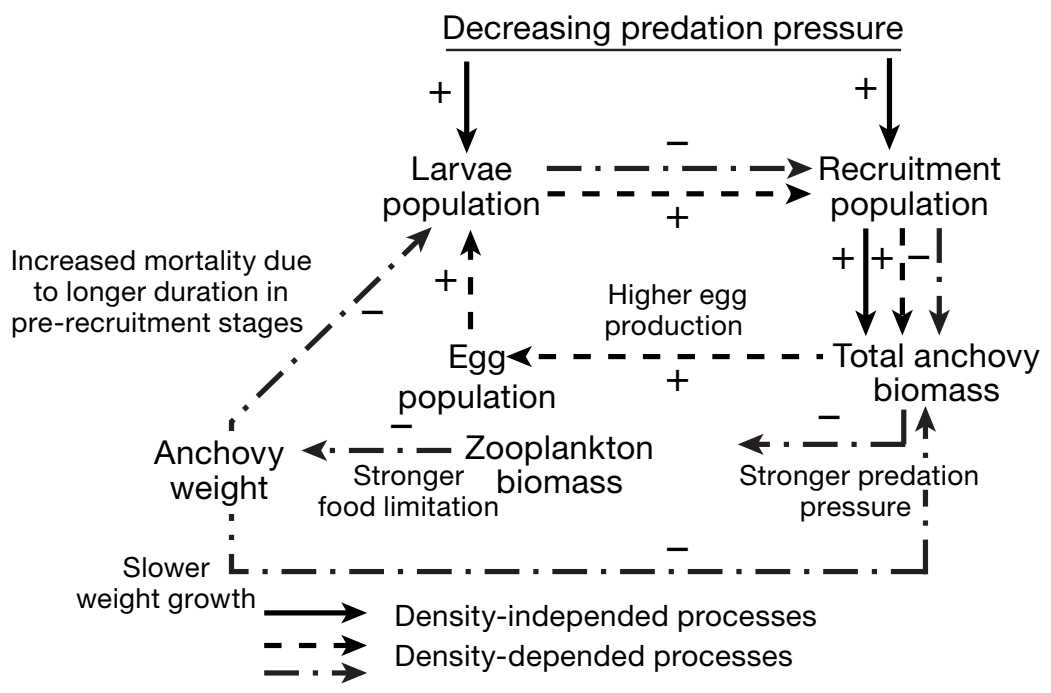

Fig. 8. Density-dependent and -independent effects on anchovy biomass resulting from decreasing predation pressure. +: positive and -: negative feedbacks 
density-dependent feedback mechanisms. Direct impact of the weakening predation pressure in the total anchocy biomass (Fig. 8) introduced a positive feedback mechanism via higher egg production and subsequent increase in larval and recruitment populations and the total anchovy biomass (Fig. 8). This contribution was partly compensated by 2 negative feedback mechanisms (Fig. 8). Higher stocks exerted stronger predation pressure on zooplankton and thus stronger food limitation, and consequently slower weight growth of anchovy. Slower weight growth also caused a longer retention of individuals at pre-recruitment stages, followed by a higher mortality rate that reduced larval and post-larval populations and, as a result, the total anchovy biomass. The positive feedback mechanism with the additional contribution of the increase in $N_{\mathrm{c}}$ apparently had a stronger influence and became increasingly more pronounced as the predation pressure decreased (Fig. 7a-c).

\section{Transition from moderate to high stock regime (TR2)}

Characteristics of the transition TR2 at the end of the 1970s in response to eutrophication of the Black Sea were explored by the simulations Moderate Stock Regime (MSR) 1, MSR2, and MSR3 (Table 8). Stock and catch versus an $N_{\mathrm{c}}$ variations (Fig. 9a,b) indicated an efficient supply of resources to anchovy for an $N_{\mathrm{c}}$ between 2.0 and $3.0 \mathrm{mmol} \mathrm{m}^{-3}$. The most drastic changes occured for the case of no jelly transport from coastal regions $\left(\kappa_{\mathrm{Z} 3}\right.$ $=0)$. Anchovy stock increased to $8 \mathrm{t} \mathrm{km}^{-2}(1200 \mathrm{kt})$ for $N_{\mathrm{C}}$ of $\sim 2.0 \mathrm{mmol} \mathrm{m}^{-3}$ and was doubled $\left(\sim 16 \mathrm{t} \mathrm{km}^{-2}\right)$ for $N_{\mathrm{C}}$ of $\sim 2.5 \mathrm{mmol} \mathrm{m}^{-3}$ (Fig. 9a), accompanied by negligibly small gelatinous biomass $\left(\sim 0.1 \mathrm{gC} \mathrm{m}^{-2}\right)$. Under the relatively low gelatinous import rate of $\kappa_{\mathrm{Z} 3}=0.0005 \mathrm{~d}^{-1}$, the anchovy stock, at $8 \mathrm{t} \mathrm{km}^{-2}(1200 \mathrm{kt})$ for $N_{\mathrm{c}}=2.5 \mathrm{mmol}$ $\mathrm{m}^{-3}$, was almost half of the $\kappa_{\mathrm{z} 3}=0$ case (Fig. 9a), but annual mean gelatinous biomass was elevated to around
$0.5 \mathrm{gC} \mathrm{m}^{-2}$ (Fig. 9c). Further increase in the gelatinous transport rate to $\kappa_{Z 3}=0.0010 \mathrm{~d}^{-1}$ exerted even stronger pressure through food competion and predation on anchovy. The anchovy stock reduced to $\sim 6 \mathrm{t} \mathrm{km}^{-2}$ (900 kt; Fig. 9a) while the gelatinous biomass increased to $\left(\sim 0.7 \mathrm{gC} \mathrm{m}^{-2}\right)$ at $N_{\mathrm{c}}$ at $\sim 2.5 \mathrm{mmol} \mathrm{m}^{-3}$. According to these simulations, the observed anchovy stock ( 1500 kt; $10 \mathrm{t}$ $\left.\mathrm{km}^{-2}\right)$, catch $\left(\sim 450 \mathrm{kt} 3.0 \mathrm{t} \mathrm{km}^{-2}\right)$, and the accompanying observed gelatinous carnivore biomass of $1.0 \mathrm{gC} \mathrm{m}^{-2}$ after the transition TR2 were possible when $N_{\mathrm{c}}$ and $\kappa_{Z 3}$ changed from their pre-transition values of $1.8 \mathrm{mmol} \mathrm{m}^{-3}$ and $0.0 \mathrm{~d}^{-1}$ to post-transition values of $3.0 \mathrm{mmol} \mathrm{m}^{-3}$ and $0.0005 \mathrm{~d}^{-1}$ (Table 10; case no. 3). Density-dependent mechanisms similar to those depicted in Fig. 8 played a critical role in the sharp increase of anchovy stock within a narrow range of $N_{\mathrm{c}}$ between 2.0 and $3.0 \mathrm{mmol} \mathrm{m}^{-3}$.

Fig. 9a-c also elucidates how stock and catch were maintained during the 1980s after the TR2 transition. For an $N_{\mathrm{c}}$ between 3.0 and $4.0 \mathrm{mmol} \mathrm{m}^{-3}$, a likely increase of $\kappa_{\mathrm{Z} 3}$ from $0.0005 \mathrm{~d}^{-1}$ to $0.001 \mathrm{~d}^{-1}$ introduced only a $1.5 \mathrm{t} \mathrm{km}^{-2}$ reduction in stock that persisted around $7.0 \mathrm{t} \mathrm{km}^{-2}$ under moderate fishing pressure values $\left(0.5\right.$ to 0.6 fyr $\left.^{-1}\right)$ during the mid-1980s (see Table 10; case no. $4 \mathrm{a}, \mathrm{b})$. The poor food consumption capacity of the gelatinous group compared to anchovy, and the preferential pathway of the food web from large phytoplankton to mesozooplankton and to anchovy retained gelatinous biomass around $1.0 \mathrm{gC} \mathrm{m}^{-2}$ up to the TR3 transition phase (Fig. 9c).

\section{Transition from high to low stock regime (TR3)}

\section{Overfishing scenario}

Setting the subsurface nitrate concentration to $N_{\mathrm{C}}=$ $3.0 \mathrm{mmol} \mathrm{m}^{-3}$ as deduced from the previous analysis, simulations HSR5 to HSR8 (Table 8) examined the role
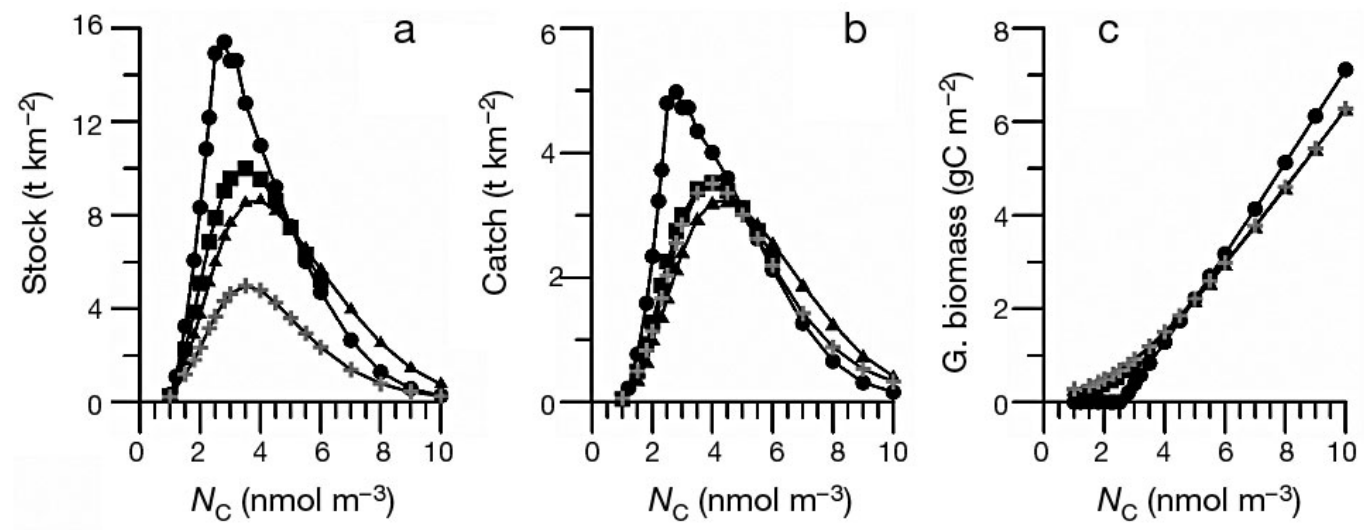

Fig. 9. Subsurface source layer nitrate concentration, $N_{c}$, versus (a) exploitable anchovy stock on 1 October, (b) total catch during the fishing season (1 October to $15 \mathrm{March}$ ), and (c) annual mean of gelatinous biomass, integrated over the euphotic zone, for the

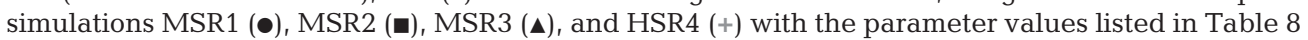


of increasing fishing pressure during the second half of the 1980 s by varying the fishing pressure $\left(m_{\mathrm{f}}\right)$ within the range 0.3 to $1.5 \mathrm{fyr}^{-1}$ for 3 different choices of $\kappa_{\mathrm{z} 3}$. The egg density and stock changes (Fig. 10a,b) were particularly pronounced for low to moderate values for the gelatinous carnivore transport rate $\left(\kappa_{\mathrm{z} 3}=0.0005\right.$ to $0.0015 \mathrm{~d}^{-1}$ ) due to weaker population loss exerted on anchovy eggs and larvae. At $m_{\mathrm{f}}$ around 0.5 to $0.7 \mathrm{fyr}^{-1}$, a maximum sustainable catch of $\sim 500 \mathrm{kt}$ (Fig. 10c) was maintained with a stock exploitation (catch to exploitable stock ratio) of up to $60 \%$ (Table 10, case no. $4 \mathrm{a}, \mathrm{b})$. The fishing pressure value of $0.7 \mathrm{fyr}^{-1}$ set a critical threshold to avoid recruitment failure and to sustain a high catch. When the fishing pressure exceeded $0.7 \mathrm{fyr}^{-1}$, recruits were exploited at an increasing rate, egg production decreased considerably, harvesting became no longer sustainable, and the catch started to decline together with the stock. In the simulations for $\kappa_{\mathrm{Z} 3}=0.0005$ and $0.0010 \mathrm{~d}^{-1}$, anchovy stock and catch fell to their observed ranges of 200 to $375 \mathrm{kt}$ (1.3 to $2.5 \mathrm{t} \mathrm{km}^{-2}$ ) and 150 to $300 \mathrm{kt}$ ( 1.0 to $2.0 \mathrm{t} \mathrm{km}^{-2}$ ), respectively, at the unrealistically high fishing pressure rate
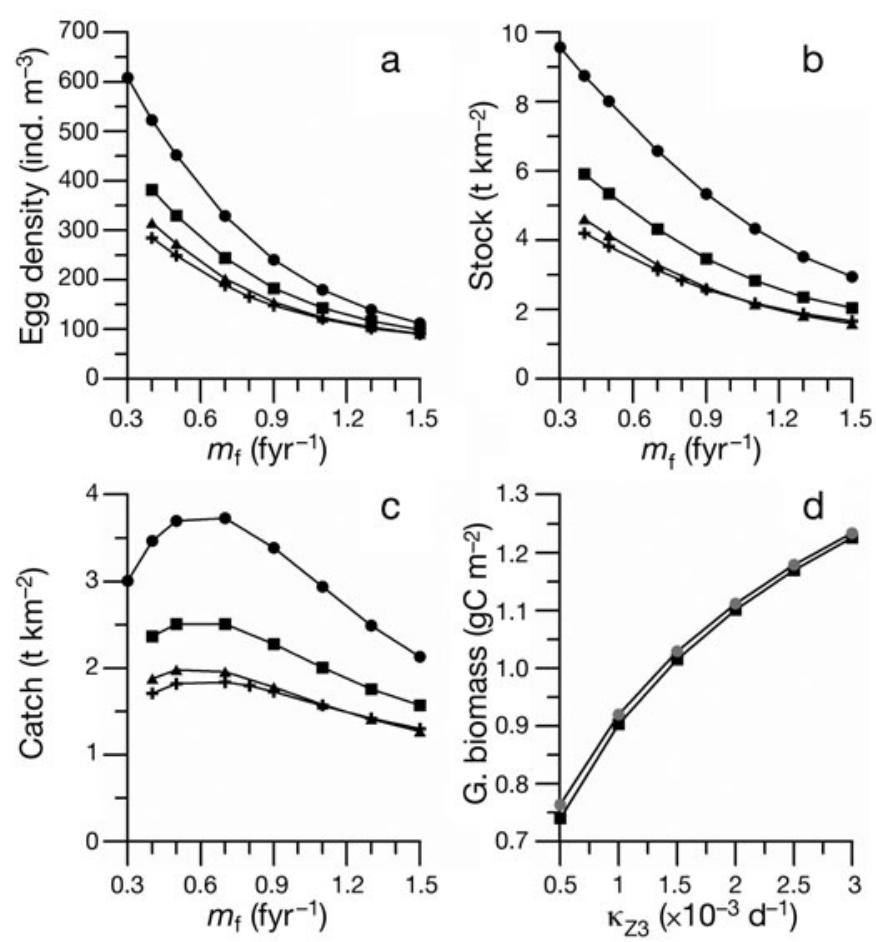

Fig. 10. Engraulis encrasicolus ponticus. Fishing mortality rate, $m_{\mathrm{f}}\left(\mathrm{fyr}^{-1}\right.$; defined as the product of daily fishing mortality rate with $165 \mathrm{~d}$ of fishing during $1 \mathrm{yr}$ ), versus (a) total number of eggs produced during the entire spawning season (1 June to 31 August), (b) exploitable stock on 1 October 1, and (c) total catch during the fishing season (1 October to $15 \mathrm{March}$ ) for

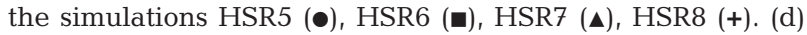
Annual mean gelatinous biomass integrated over the euphotic zone for the simulations HSR9 (॰) and HSR10 (घ). The parameter values for the simulations are listed in Table 8 $m_{\mathrm{f}}=1.5 \mathrm{fyr}^{-1}$ (equivalent to $3.26 \mathrm{yr}^{-1}$; Fig. 10b,c) for the late 1980s (Ivanov \& Panayotova 2001, Bilgin 2006). For a more realistic choice of fishing pressure of $\sim 0.8 \mathrm{fyr}^{-1}\left(1.75 \mathrm{yr}^{-1}\right)$, stock and catch exceeded the empirical data by $\sim 150$ to $200 \mathrm{kt}$ for lower values of $\kappa_{\mathrm{Z} 3}$ (simulations HSR5 and HSR6). More importantly, the annual-mean gelatinous biomass of $\sim 0.7 \mathrm{gC} \mathrm{m}^{-2}$ was 4 times lower than its reported values (Fig. 2). For the choice of $\kappa_{\mathrm{Z} 3}=0.0025 \mathrm{~d}^{-1}$ (simulation HSR7), even though a higher rate of gelatinous predation on anchovy eggs and larvae reduced the stock to $\sim 400 \mathrm{kt}$ and catch to $\sim 200 \mathrm{kt}$ in agreement with the observed data (Table 10; case no. 5a), the gelatinous biomass increased only up to $1.2 \mathrm{gC} \mathrm{m}^{-2}$.

During the 1980s, the marked rise of the medium pelagic stock (Oguz 2007) likely imposed stronger predation pressure on anchovy. Its increase from 0.0002 to $0.0003 \mathrm{~m}^{3} \mathrm{~d}^{-1}$, together with $m_{\mathrm{f}}=0.8 \mathrm{fyr}^{-1}$ and $\kappa_{\mathrm{z} 3}=$ $0.0015 \mathrm{~d}^{-1}$ (simulation HSR8), is also a likely scenario that can explain observed stock and catch values (Table 10; case no. 5b), but gelatinous biomass remained at $\sim 1.0 \mathrm{gC} \mathrm{m}^{-2}$.

As depicted in Fig. 10d, almost identical gelatinous biomass variations for both low and high choices of fishing mortality rate $\left(m_{\mathrm{f}}=0.3\right.$ and $\left.0.8 \mathrm{fyr}^{-1}\right)$ for any choice of $\kappa_{\mathrm{z} 3}$ suggest that the number of eggs and larvae produced by female adult anchovies is always higher than the amount consumed by the gelatinous group, irrespective of fishing pressure. In fact, reduced anchovy egg and larval populations due to increasing fishing pressure from 0.3 to $0.8 \mathrm{fyr}^{-1}$ decreased gelatinous biomass only by $0.2 \mathrm{gC} \mathrm{m}^{-2}$. All of these simulations suggested that overfishing together with changes in the piscivore predation rate and/or gelatinous predation rate could give rise to the observed anchovy collapse, but could not cause the simultaneous observed rise in gelatinous biomass.

\section{Nutrient enrichment scenario}

Concurrent changes in $N_{\mathrm{c}}$ and $m_{\mathrm{f}}$ beyond their respective thresholds of $4.0 \mathrm{mmol} \mathrm{m}^{-3}$ and $0.7 \mathrm{fyr}^{-1}$ are an alternative likely cause of the anchovy-Mnemiopsis shift. The case of a sufficiently enriched and overfished system that was examined by the parameter settings of HSR4 (Table 8) results in the anchovy and gelatinous biomass and anchovy catch variations shown in Fig. $9 \mathrm{a}-\mathrm{c}$, and the phytoplankton and total microand mesozooplankton biomass variations shown in Fig. 11 with respect to the changes in source layer nitrate concentration, $N_{\mathrm{c}}$. The $x$-axes in these plots may also be interpreted to represent nitrate flux from the subsurface source layer $\left(N F_{\mathrm{c}}\right)$ defined by a constant $N_{\mathrm{c}}$ and a varying entrainment rate. For example, for $N_{\mathrm{c}}=$ 
$4.0 \mathrm{mmol} \mathrm{m} \mathrm{m}^{-3}$, a 25 to $50 \%$ increase in the standard winter entrainment rate to $w_{\mathrm{e}}=0.05$ to $0.06 \mathrm{~d}^{-1}$, amounts to $N F_{\mathrm{c}} \sim 0.20$ to $0.24 \mathrm{mmol} \mathrm{m}^{-3} \mathrm{~d}^{-1}$. In terms of the standard winter entrainment rate $\left(w_{\mathrm{e}}=0.04 \mathrm{~d}^{-1}\right)$, it is equivalent to an $N_{\mathrm{C}}$ increase of 5.0 to $6.0 \mathrm{mmol} \mathrm{m}^{-3}$ in Figs. $9 \& 11$.

According to the simulation HSR4, increasing $N_{\mathrm{c}}$ beyond its threshold resulted in a linear increase of the euphotic zone annual-mean phytoplankton biomass (Fig. 11). The zooplankton biomass instead maintained a steady level (Fig. 11), reflecting heavy consumption by the gelatinous group due to the linear dependence of its growth on zooplankton biomass (Eq. A7), giving the gelatinous group a competitive advantage in the consumption of resources compared to anchovy at high resource productivity. Gelatinous biomass therefore grew linearly with increasing food availability (Fig. 9c), built up stronger predation pressure on anchovy eggs and larvae, and severely limited biomass growth of anchovy recruits and adults and their competitive ability to feed on zooplankton. The reduced anchovy biomass (Fig. 9a) then limited the spawning size of adult female anchovy (Eq. 2).

During the TR3 transition, the observed anchovy stock of $350 \mathrm{kt}\left(\sim 2.5 \mathrm{t} \mathrm{km}^{-2}\right)$ and the annual mean gelatinous biomass of $3.0 \mathrm{gC} \mathrm{m}^{-2}$ under high fishing pressure conditions of $0.8 \mathrm{fyr}^{-1}$ corresponded to an $N_{\mathrm{c}}$ of ca. $6.0 \mathrm{mmol} \mathrm{m}^{-3}$ (or $N F_{\mathrm{c}}$ of $\sim 0.24 \mathrm{mmol} \mathrm{m}^{-3} \mathrm{~d}^{-1}$ ) (Fig. 9). This implies that a $50 \%$ increase in the entrainment rate can indeed provide the required nutrient flux into the surface layer to maintain a sufficient resource carrying capacity that can promote the anchovy-Mnemiopsis shift. The parameter values of this simulation

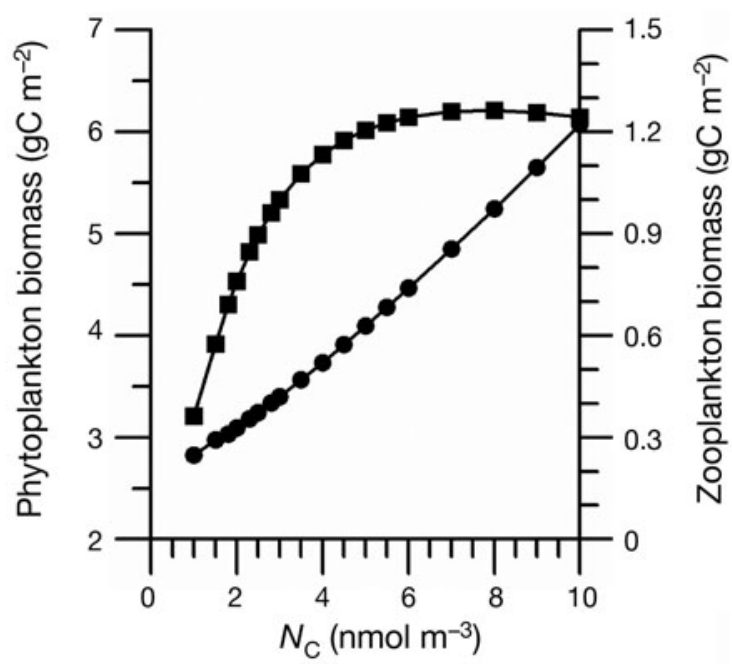

Fig. 11. Subsurface source layer nitrate concentration, $N_{\mathrm{c}}$ versus total phytoplankton biomass (•) and sum of micro- and mesozooplankton biomass ( $\boldsymbol{\square}$ ) integrated over the euphotic layer for the simulation HSR4 in Table 8 are listed in Table 10 (case no. 5c). The corresponding annual-mean euphotic zone-integrated phytoplankton biomass of $\sim 4.5 \mathrm{gC} \mathrm{m}^{-2}$ and prey organisms (the sum of micro- and meso-) zooplankton biomass of $\sim 1.2 \mathrm{gC} \mathrm{m}^{-2}$ (Fig. 11) agreed roughly with the data given by Shushkina et al. (1998) and were also consistent with earlier modeling studies (e.g. Lebedeva \& Shushkina 1994, Oguz et al. 2001).

The same transition under low fishing pressure $\left(0.3 \mathrm{fyr}^{-1}\right)$, on the other hand, required an $N_{\mathrm{c}}$ enrichment as high as $\sim 8.0 \mathrm{mmol} \mathrm{m}^{-3}$ (or $N F_{\mathrm{c}}$ of $\sim 0.32 \mathrm{mmol}$ $\mathrm{m}^{-3} \mathrm{~d}^{-1}$; Fig. 9a). This level of enrichment needs a 2-fold higher entrainment rate, which may be too high for the late 1980s Black Sea environmental conditions. Nevertheless, it was instructive to show that the enrichment mechanism alone may produce the anchovygelatinous shift irrespective of fishing pressure at higher productivity levels. It further suggests that a $50 \%$ increase in the entrainment rate (as in our collapse scenario) under the low fishing pressure conditions may simulate the observed gelatinous biomass of $3 \mathrm{gC} \mathrm{m}^{-2}$, but reveals a 2-fold higher anchovy stock $\left(\sim 5.0 \mathrm{t} \mathrm{km} \mathrm{km}^{-2}\right.$ or $\left.750 \mathrm{kt}\right)$. Overfishing and nutrient enrichment therefore almost equally contributed to the TR3 transition. The enrichment mainly caused gelatinous biomass to rise from 1.3 to $3.0 \mathrm{gC} \mathrm{m}^{-2}$, whereas increasing fishing pressure reduced the anchovy stock from 5.0 to $2.5 \mathrm{t} \mathrm{km}^{-2}$.

Starting from settings of the HSR in 1978 (Table 10, case no. 3), TR3 was also reproduced by a time-dependent simulation (TDS1 in Table 8) that incorporated a temporally varying nutrient flux (Fig. 12a) and fishing mortality rate (Fig. 12b). The smoothed winter-mean sea surface temperature (Fig. 12a) was assumed to be a proxy for nitrate flux variations from $0.12 \mathrm{mmol} \mathrm{m}^{-3}$ $\mathrm{d}^{-1}\left(w_{\mathrm{e}}=0.04 \mathrm{~d}^{-1}, N_{\mathrm{c}}=3.0 \mathrm{mmol} \mathrm{m}^{-3}\right)$ at the begining of the $1980 \mathrm{~s}$ to $0.19 \mathrm{mmol} \mathrm{m} \mathrm{m}^{-3} \mathrm{~d}^{-1}\left(w_{\mathrm{e}}=0.05 \mathrm{~d}^{-1}, N_{\mathrm{c}}=\right.$ $3.6 \mathrm{mmol} \mathrm{m}^{-3}$ ) in 1988 . The change in fishing mortality rate resembled the data given by Ivanov \& Panayotova (2001) and increased from $0.22 \mathrm{fyr}^{-1}$ in 1978 to more than 0.80 fyr $^{-1}$ in $1987-1988$ in response to an increase in Turkish fishery efforts (Bilgin 2006). It then decreased linearly down to $\sim 0.5 \mathrm{fyr}^{-1}$ in 1991 due to reduced catchability of stocks.

With this idealized representation of the control mechanisms, anchovy and gelatinous groups maintained a stock size of $9.5 \mathrm{t} \mathrm{km}^{-2}$ (Fig. 12b) and $\sim 1.0 \mathrm{gC}$ $\mathrm{m}^{-2}$ (Fig. 12c), respectively, under a relatively low fishing pressure of $\sim 0.3 \pm 0.09 \mathrm{fyr}^{-1}$ and nitrate flux of $\sim 0.13 \pm 0.015 \mathrm{mmol} \mathrm{m}^{-3} \mathrm{~d}^{-1}$ from 1980 to 1984 . As nitrate flux increased to $0.15-0.18 \mathrm{mmol} \mathrm{m}^{-3} \mathrm{~d}^{-1}$ in 1985 to 1986 , gelatinous biomass increased to $1.7 \mathrm{gC}$ $\mathrm{m}^{-2}$ at the expense of anchovy stocks, which declined to $7.0 \mathrm{t} \mathrm{km}^{-2}$. Further increase in both nitrate flux and fishing pressure during 1987 to 1988 caused the 

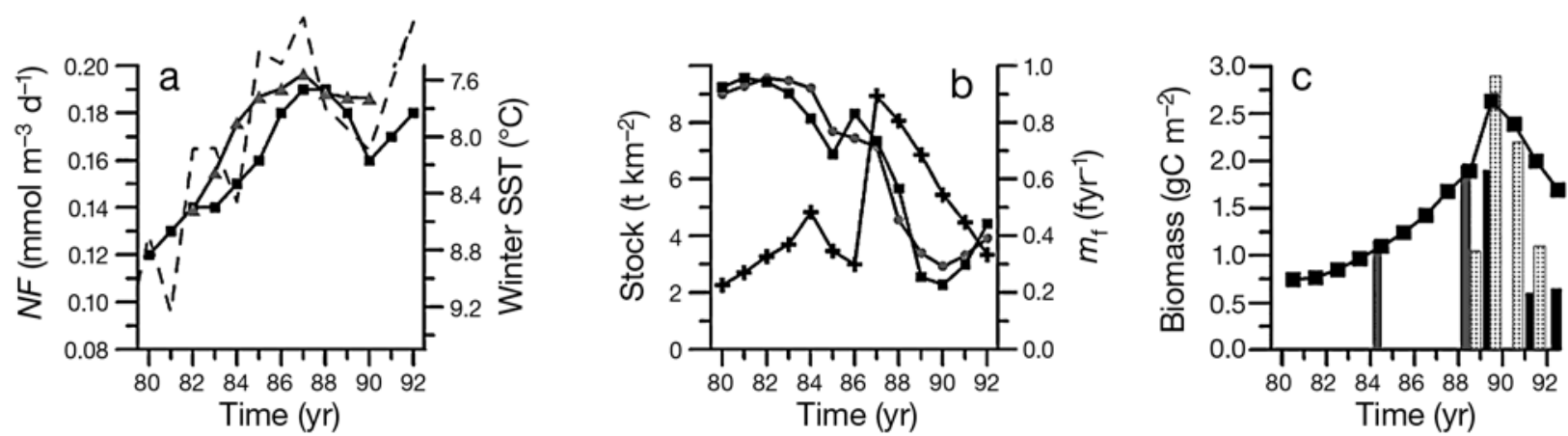

Fig. 12. Time series of (a) winter-mean (December to March) sea surface temperature (SST, dashed line) and its smoothed version ( ()$_{)}$, and prescribed nitrate flux, $N F_{1}(\boldsymbol{\square})$ at the base of the euphotic layer; (b) prescribed fishing mortality rate (fyr ${ }^{-1}$; defined as in Fig. 10) (+), and observed (๘) and (•) simulated anchovy stock ( $\mathrm{km}^{-2}$ ), (c) observed Aurelia aurita biomass (gray bars) and Mnemiopsis leidyi biomass during spring (black bars) and August-September (dotted bars), and simulated total annual mean gelatinous biomass (匹) for the simulation TDS1 in Table 8

anchovy-Mnemiopsis shift in 1989 as described above. We note that the nitrate flux necessary to trigger the shift in the time-dependent simulation was approximately $0.04 \mathrm{mmol} \mathrm{m}^{-3} \mathrm{~d}^{-1}$ less than its value found in our previous equilibrium analysis.

\section{DISCUSSION AND CONCLUSIONS}

We employed a coupled LTL-anchovy model to understand the causes of 3 specific sharp changes in anchovy stocks and the interactions between anchovy and gelatinous carnivores during the critical period of radical ecosystem transformation from the late 1960s to the late 1980s in the Black Sea. The explicit representation of anchovy population and weight growth dynamics permitted a more accurate estimation of stock changes and gelatinous predation exclusively on anchovy eggs and larvae. Despite its simplicity, the anchovy model was able to simulate major features of life history characteristics within the limitations of the present study. The main focus of the present study was to explore how piscivorous and gelatinous predation pressures, fishing mortality, nutrient enrichment of the biologically productive layer due to simultaneous effects of eutrophication and climate-induced intensified vertical mixing, and related density-dependent processes controlled long-term behavior of the food web with a special emphasis on anchovy and gelatinous biomass variations.

\section{Interpretation of results in terms of the intraguild predation (IGP) theory}

The simulations with various combinations of 4 control parameters surmised that the transition from the low to the moderate quasi-stable stock regime (TR1) was primarily controlled by the changes in $m_{1}$ and $N_{\mathrm{c},}$ that from the moderate to the high stock regime (TR2) by $\kappa_{\mathrm{z} 3}$ and $N_{\mathrm{c},}$ and the backward transition (TR3) to the low stock regime by $m_{\mathrm{f}}$ and $N_{\mathrm{c}}$. Each of these transition events was affected to a different extent by the nutrient enrichment process in addition to one of the other factors. The present section interprets the long-term development of anchovy (consumer) biomass relating to its resource and predator biomass, with of nutrient enrichment of the system used as a proxy for the resource carrying capacity.

Fig. 13 displays anchovy, gelatinous, total herbivore, and omnivore zooplankton biomass variations versus subsurface nitrate concentration $\left(N_{\mathrm{c}}\right)$ and nitrate flux $\left(N F_{\mathrm{c}}\right)$ as the system changed from low to higher production regimes over 2 decades. It provides a simplified view of the Black Sea anchovy-gelatinous interactions using 2 model solutions for the low and high fishing pressure conditions. On the $x$-axis, nitrate flux serves as a better measure of nutrient enrichment of the euphotic zone, particularly for the TR3 transition period because it was characterized by a constant $N_{\mathrm{c}}$ and varying entrainment rate. On the other hand, the $N_{\mathrm{c}}$ axis is easier for interpreting the TR1 and TR2 transitions since they were governed by the changing nutrient content that was supplied from the chemocline into the euphotic layer at a constant entrainment rate. Fig. 13 can be compared to similar figures used in other IGP models (Fig. 14a,b) that investigated the changes of 2 different intraguild system properties along a productivity gradient.

Consistent with the IGP models (e.g. Diehl \& Feibel 2000, Mylius et al. 2001), Fig. 13 revealed 4 distinct regimes of the zooplankton-anchovy-gelatinous system. A low $N_{\mathrm{c}}$ range below $1.0 \mathrm{mmol} \mathrm{m}^{-3}$ corresponded to the resource-only regime with very low productivity (denoted by R). Available nutrients in the euphotic zone sustained only a low zooplankton biomass (the sum of micro- and mesozooplankton) that was not able to support growth of the consumer and predator species. The 


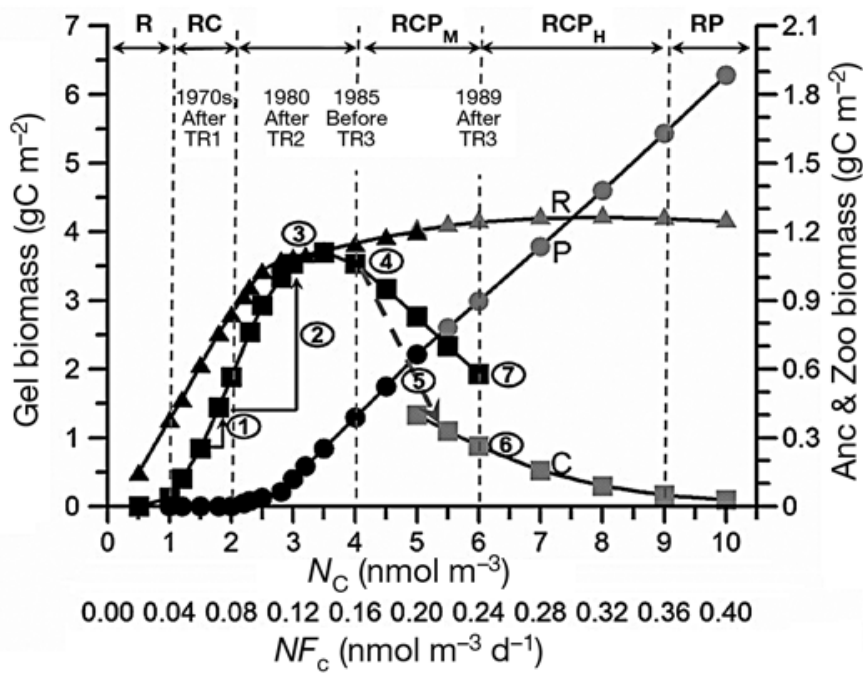

Fig. 13. Gelatinous (Gel) biomass $(\bullet, \bullet)$, exploitable anchovy (Anc) stock $(\boldsymbol{\Lambda}, \Delta)$ and annual-mean total zooplankton (Zoo) biomass $(\mathbf{\square}, \mathbf{m})$ versus subsurface nitrate concentration, $N_{\mathrm{C},}$ and nitrate flux, $N F_{\mathrm{c}}$. The black and gray symbols show, respectively, the simulation MSR2 (low fishing scenario) for low-to-moderate enrichment regime and the simulation HSR4 (high fishing scenario) for moderate-to-high enrichment regime listed in Table 8. Broken line with arrow represents the change of anchovy biomass from low to high fishing scenario simulations during enrichment of the system. R: resource (the sum of micro- and mesozooplankton), C: consumer (anchovy), P: predator (gelatinous zooplankton) biomass. The numbers in circles refer to the changes in anchovy stock due to (1) increase in $m_{1}$, (2) increase in $N_{\mathrm{c}}$ and (3) leveling off due to increasing gelatinous predation, (4) decrease in anchovy stock due to gelatinous predation and competitive exclusion, (5) additional decrease due to overfishing, (6) the anchovy-Mnemiopsis shift due to higher enrichment at high fishing pressures, and (7) alternative anchovyMnemiopsis shift at low to moderate fishing pressures

range $1.0<N_{\mathrm{C}} \leq 2.0 \mathrm{mmol} \mathrm{m}^{-3}$ represented the low productivity, zooplankton-anchovy regime of the early 1970s (denoted by RC). The gelatinous group was excluded from the system due to the competitive advantage of anchovy of consuming resources more effectively, set in the model by $c_{1}>r_{\mathrm{Zz}}$ (Tables $4 \& 6$ ). As suggested by Holt \& Polis (1997), this is a necessary con- dition for the existence of omnivory at sufficiently high carrying capacity of an IGP system.

In the RC regime, $20 \%$ enrichment of the subsurface nitrate source layer together with weakening of the piscivore predation pressure to half of its pre-transition value promoted a 2 -fold change in anchovy stock from the low regime $(\sim 300 \mathrm{kt})$ to the moderate regime $(\sim 700 \mathrm{kt})$ at the end of the 1960s (see Fig. 13, number 1). Each of these mechanisms contributed almost equally to the anchovy stock rise. The change would not have occured without the predation pressure change across its threshold range (Fig. 7). Once the predation pressure change initiated the transition, the enrichment effect made it stronger and easier, at a lower range of predation pressure changes, by compensating for slowed weight growth of early life stages with population increase and by favoring higher egg production. Increasing the nutrient enrichment level up to about $2.2 \mathrm{mmol} \mathrm{m}^{-3}$ with no change in predation pressure, or reducing predation pressure by an additional $50 \%$ with no enrichment, could also provide a similar stock increase (Figs. $7 b$ \& 9b). However, these alternatives imposed more stringent conditions compared to smaller but simultaneous changes in enrichment and piscivorous predation pressure.

Subsurface nitrate concentrations ranging between 2.0 and $4.0 \mathrm{mmol} \mathrm{m}^{-3}$ corresponded to the growing effect of intense eutrophication in the 1970s and 1980s (Fig. 2) and represented the lower range of the coexistence regime of anchovy and gelatinous species (denoted by $\mathrm{RCP}_{\mathrm{L}}$ ) in Fig. 13. In this regime, a further increase in food resources together with prevailing conditions of low predator and low-to-moderate fishing pressures supported a favorable weight growth at the individual level and density-dependent biomass growth at the population level, and resulted in a 2-fold change in anchovy stock during the late 1970s (see Fig. 13a, number 2). As the enrichment was building up, jellies started to coexist with anchovy at low biomass levels $\left(<1.0 \mathrm{gC} \mathrm{m}^{-2}\right)$, but they did not exert a strong control on anchovy because of their competitive disadvantage of consuming prey at low carrying ca-
Fig. 14. (a) Equilibrium densities of resource, consumer, and predator groups versus resource carrying capacity reproduced from Fig. 1 in Diehl \& Feibel (2000). (b) Population densities of resource, consumer and predator groups versus resource carrying capacity reproduced from Fig. 4 in Mylius et al. (2001)

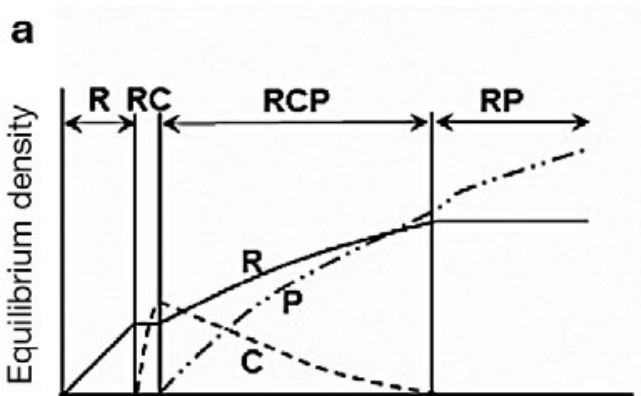

Resource carrying capacity

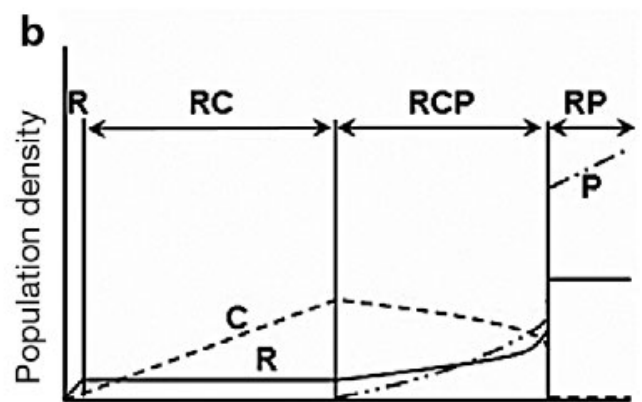

Resource carrying capacity 
pacity. The $N_{\mathrm{c}}$ range between 3.0 and $4.0 \mathrm{mmol} \mathrm{m}^{-3}$ (or the nitrate flux range of $N F_{\mathrm{C}}$ ca. 0.12 to $0.16 \mathrm{mmol} \mathrm{m}^{-3}$ $\mathrm{d}^{-1}$ ) provided the optimum conditions for low gelatinous biomass (ca. $1.0 \mathrm{gC} \mathrm{m}^{-2}$ ) and high anchovy stock (>1000 kt) that persisted during the first part of the 1980s (see Fig. 13, number 3).

The range $0.16<N F_{\mathrm{c}} \leq 0.24 \mathrm{mmol} \mathrm{m}^{-3} \mathrm{~d}^{-1}$ represented the moderate enrichment level of the coexistence regime (denoted by $\mathrm{RCP}_{\mathrm{M}}$ ) and applied to the second part of the 1980s (see Fig. 13, number 4). Sustained higher nutrient flux into the euphotic layer during this period promoted more intense primary and secondary production (Fig. 11), which then gave rise to more efficient nutrient recycling in spring and summer months. The enhancement in food resources altered the food web dynamics in favor of gelatinous carnivores because of their ability to consume the shared resources more effectively than anchovy eggs and larvae at higher carrying capacity of the system. Their linear dependence of growth on resources resulted in biomass increases at a rate of $0.9 \mathrm{gC} \mathrm{m}^{-2}$ per $0.04 \mathrm{mmol}$ $\mathrm{m}^{-3} \mathrm{~d}^{-1}$ nitrate flux. The gradually weakening rate of increase of the total annual-mean micro- and mesozooplankton biomass in the $\mathrm{RC}$ regime up to 0 in the $\mathrm{RCP}_{\mathrm{M}}$ regime and afterwards indicate their high resource consumption. Eventually, the gelatinous group became the main consumer of zooplankton and reduced the availability of zooplankton for anchovy. In addition to competitive disadvantages and predation by the gelatinous group, adult anchovy were harvested at increasing proportions (see Fig. 13, number 5). As a result, anchovy stocks declined to $\sim 300 \mathrm{kt}$ (see Fig. 13, number 6). Approximately $50 \%$ of the anchovy stock depletion was caused by competition with and predation by Mnemiopsis, and the remainder by increasing fishing pressure beyond its threshold of $0.7 \mathrm{fyr}^{-1}$. The fishery served to speed up the collapse, rather than driving the shift between anchovy and Mnemiopsis. Under the same enrichment level, a Mnemiopsis biomass of $\sim 3.0 \mathrm{gC} \mathrm{m}^{-2}$ could coexist with moderate levels of anchovy stock ( 500 to $700 \mathrm{kt}$ ) if the fishery was maintained around 0.3 to $0.5 \mathrm{fyr}^{-1}$ (see Fig. 13, number 7).

The higher range $\left(0.24<N F_{\mathrm{c}} \leq 0.36 \mathrm{mmol} \mathrm{m}^{-3} \mathrm{~d}^{-1}\right)$ of the coexistence regime $\left(\mathrm{RCP}_{\mathrm{H}}\right)$ was characterized by a very low anchovy biomass $(<200 \mathrm{kt})$ and a further increase in gelatinous biomass of up to $6.0 \mathrm{gC} \mathrm{m}^{-2}$. It was followed by the predator-only regime (RP) at $N F_{\mathrm{c}}$ $\geq 0.36 \mathrm{mmol} \mathrm{m}^{-3} \mathrm{~d}^{-1}$, in which anchovy became extinct and gelatinous biomass invaded the system at high quantities. The latter 2 regimes were provided here for completeness and were not significant in terms of observed conditions in the Black Sea. The anchovyMnemiopsis transition event corresponded to moderate enrichment of the system shown by number 6 in Fig. 13.
Fig. 13 is similar to the equilibrium density structure of the tri-trophic level intraguild system analyzed by Diehl \& Feibel (2000, hereafter referred to as DF; Fig. 14a). A common feature in both models were smooth transitions between the consumer-only and the predator-only states (or, more generally, the high consumer-low predator state and vice versa). These states were separated by a broad, transitional moderate enrichment domain in which both the consumer and the predator existed at different proportions. This structure signified a single equilibrium state of the system, i.e. the system attained only 1 possible state for any value of the carrying capacity. The forward and backward transitions between the alternate states occur along the same trajectory under the same environmental conditions or along a different trajectory if the conditions change.

In contrast, the tri-trophic level model given by Mylius et al. (2001; hereafter referred to as MKRP model) described a different structure. The consumer (predator) population density decreased (increased) only slightly over a broader range of the carrying capacity in the high consumer-low predator state and became extinct abruptly at the threshold of low consumer-high predator state (Fig. 14b). When the system was initially in the low consumer-high predator state, a similar discontinuous transition to the other state occured at a different (lower) threshold of the carrying capacity. The system thus possessed 2 alternative states for a certain range of the carrying capacity and multiple equilibria. For such systems, transitions are constrained by more severe threshold conditions, and they can occur only at particular threshold values of the carrying capacity, in contrast to a broader transition zone for a system in single equilibrium state. Thus, the sytems in single and multiple equilibria possess 2 contrasting biomass/population density structures at moderate carrying capacities (see Fig. 14).

According to our model results, an anchovy stock of $\sim 300 \mathrm{kt}$ was not too low, and $\sim 3 \mathrm{gC} \mathrm{m}^{-2}$ gelatinous biomass was not too high to consider the anchovy-Mnemiopsis transition a true regime shift of the system to the low anchovy-high gelatinous alternate stable state. It instead appears to be a sporadic event within the transitional coexistence domain. According to observations by Shiganova \& Bulgakova (2000), the anchovy-Mnemiopsis system remained in the transitional domain at different biomass combinations during the first half of the 1990s and then moved gradually back to the former (high anchovy-low gelatinous) stable state once strong cooling- and wind-induced mixing became no longer effective, subsurface nitrate concentration started to decline due to a decrease of eutrophication, and fishing pressure was at moderate levels during the second half of the 1990s (Oguz \& Gilbert 2007). The system even- 
tually stabilized in this state following the settlement of Beroe ovata, a predator of Mnemiopsis, into the Black Sea at the end of the 1990s.

We note that the anchovy biomass changes shown in Fig. 13 may also be interpreted in terms of the conceptual model of wasp-waist control of small pelagics (Bakun 2006; Fig. 4). The $\mathrm{RCP}_{\mathrm{L}}$ domain of enrichment corresponds to Bakun's so-called 'breakout region' of high anchovy biomass at low mortalities. The $\mathrm{RCP}_{\mathrm{H}}$ and RP domains represent the 'predator pit' of low anchovy biomass at high mortalities. The $\mathrm{RCP}_{\mathrm{M}}$ corresponds to the transitional domain between the 'breakout region' and the 'predator pit.'

Van de Wolfshaar et al. (2006) introduced size-structured populations of consumer and predator species, as well as their size-dependent foraging and fooddependent growth capacities. They noted that a more detailed representation of population and weight growth dynamics of consumer and predator species decreased the likelihood of their coexistence and allowed the predator to invade the coexistence regime and to exclude the consumer at lower carrying capacities. However, it is not clear how the model results of van de Wolfshaar et al. (2006) apply to the Black Sea, because the model is based on interactions between fish species with very different life cycle characteristics. Instead, it may be more appropriate to extend our model by explicitly incorporating selective consumption of different zooplankton species groups on the gelatinous and anchovy weight growth. However, these modifications are a major undertaking and require a rich empirical data set. Nevertheless, the main dynamics presented in this study should not change.

\section{Comparison of model results to observations}

The first transition of anchovy stock (TR1) at the end of the 1960s was caused by both direct and densitydependent effects of weakening piscivore predation pressure and slight enrichment of the basin during the early eutrophication phase. Density-dependent mechanisms made the anchovy stock response to predation losses was highly nonlinear decreasing predation pressure values. Even a 2-fold higher anchovy stock change could be possible for a slightly higher predation pressure loss. Accumulation of nutrients in the chemocline during the next decade due to the increasing effects of eutrophication caused the subsequent stock rise (TR2) at the end of the 1970s. The high stock regime (>1000 kt) and maximum sustainable catch of $\sim 500 \mathrm{kt}$ were maintained during the first part of the 1980 s at a fishing pressure range of 0.6 to $0.7 \mathrm{fyr}^{-1}$ (= 1.30 to $1.52 \mathrm{yr}^{-1}$ ) as observed along the Turkish coast (Bilgin 2006).
The second half of the 1980s saw very interesting ecological changes. Concurrently with the eutrophication-induced nutrient accumulation in the chemocline, the Black Sea experienced 2 subsequent key phenomena during the mid-1980s. One was the acclimation of Mnemiopsis to local conditions and its spreading throughout the basin following its introduction during the early 1980s. The second was the change in regional climate to a severe winter mode in 1985.

In the model, the effect of climate change was limited to the strengthening of vertical mixing in the water column, providing higher nutrient flux into the euphotic layer and subsequently leading to a higher resource carrying capacity. The change in basin-averaged Mayto-November phytoplankton biomass roughly from 15 to $20 \mathrm{~g} \mathrm{~m}^{-2}$ and annual-mean zooplankton biomass from 7 to $15 \mathrm{~g} \mathrm{~m}^{-2}$ during the second half of the $1980 \mathrm{~s}$ may likely reflect the effect of this mechanism (see Fig. 3a,b in Oguz \& Gilbert 2007). The high plankton productivity partly compensated for the excessive anchovy harvesting and the density-dependent negative effects of colder water temperatures on anchovy weight growth. More importantly, the major part of the enhanced resource production was used to support the growth of the gelatinous population. At high food concentrations, the growth and reproductive advantage of Mnemiopsis with respect to Aurelia and their food consumption advantage relative to anchovy gave them an opportunity to grow disproportionately without reaching saturation. Their increasing predation pressure on anchovy eggs and larvae reduced anchovy recruitment biomass and weakened the competitive ability of anchovy against Mnemiopsis. These mechanisms, together with high anchovy harvesting, inevitably caused recruitment failure, and the stock collapsed to about $300 \mathrm{kt}$ within 2 yr. Observational evidence of recruitment failure 1 yr before the collapse was provided by Gücü (2002).

Some investigators (e.g. Vinogradov et al. 1996, Lisovenko et al. 1997, Gordina et al. 1998, Shiganova \& Bulgakova 2000, Kideys 2002, Schulman \& Yuneva 2002) qualitatively related the anchovy collapse to (1) excessive consumption of eggs and larvae by Mnemiopsis, (2) diversion of food resourses to Mnemiopsis, (3) selective feeding of Mnemiopsis on small copepods and shift of anchovy larval diet to low-calorie food (Cladocera, Cirripedia, Ostracoda, and Bivalvia) and thus less efficient anchovy weight growth. According to the simulations, among the factors listed above, the first hypothesis does not seem to be very critical for the anchovy collapse. About $0.5 \mathrm{t} \mathrm{km}^{-2}$ annual loss of anchovy biomass due to consumption of anchovy eggs and larvae by Mnemiopsis in our model corresponded to $20 \%$ of the loss due to harvesting. In terms of stock, the role of predation may not be as crucial, but the loss of eggs 
and larvae was critical in terms of recruitment failure. On the other hand, our model did not incorporate selective feeding by Mnemiopsis and anchovy on zooplankton species. We therefore cannot assess the contribution of the third hypothesis. Under the present model setting, as described above, our results showed that the second hypothesis (i.e. diversion of enhanced food resources to Mnemiopsis) accounted for $50 \%$ of the anchovy loss and the other half came from overfishing. Nonlinear coupling of these 2 independent processes amplified the collapse, although neither would be able to individually impose such a severe stock change. Observational support for the increased variability of exploited fish stocks due to the nonlinearly amplifying effects of fishing pressure and environmental noise (which in our case is the eutrophication and climateinduced increase in gelatinous predation pressure) has been documented for the southern sector of the California ecosystem (Anderson et al. 2008).

The trend of Mnemiopsis population growth following its settlement into the Black Sea is not precisely known due to the lack of observations during the critical period of the mid-1980s. In our model, its sudden outburst in 1988-1989 was solely related to climateinduced resource enhancement during the cold climate regime of 1985 to 1987 . According to our results, gelatinous species (either Aurelia or Mnemiopsis) would not be able to rise above 1.0 to $1.5 \mathrm{gC} \mathrm{m}^{-2}$ under the prevailing conditions of eutrophication without the climate-induced enhancement of resource productivity. Anchovy would then be able to maintain a moderate stock regime (between 500 and $700 \mathrm{kt}$ ) even in the case of intense fishery $\left(0.8 \mathrm{fyr}^{-1}\right.$ or $\left.1.75 \mathrm{yr}^{-1}\right)$. Our results therefore do not support the view that eutrophication was the main mechanism that drove the Mnemiopsis population outburst in the Black Sea. Rather, it pre-conditioned the system to high resource availability under intensified mixing.

Physiological adaptations to relatively cold winter and spring surface waters (Purcell 2005) and behavioral adaptations to local feeding conditions may also be responsible for the delay in active reproduction and growth, and ultimately the population outburst of Mnemiopsis, to the following relatively warm phase in 1989 to 1991. Observations along the northeastern Black Sea (Shiganova et al. 2001, Vinogradov et al. 2005) showed a 5-fold decrease in Mnemiopsis biomass during the cold summers of 1992, 1993, and 2003 compared to other years. Shiganova et al. (2001) reported low spring and late-summer production due to low adult overwintering survival rates under severe winter conditions. A more precise formulation of temperature-dependent reproduction and growth characteristics of Mnemiopsis, together with interannual changes of the euphotic layer temperature structure, may allow the present model to examine their growth strategy.

Our study did not explicitly incorporate interannual changes in water temperature and turbulence characteristics on anchovy population and weight growth dynamics. For example, an almost $2.0^{\circ} \mathrm{C}$ decrease in the winter SST, which coincided with the general declining trend of the anchovy stock during the 1980s, may have physiologically slowed down the anchovy weight growth and indirectly reduced the year-class strength (e.g. Ottersen et al. 2001, Attrill \& Power 2002, MacKenzie \& Koster 2004). When low winter temperatures of the mixed layer extended into summer months, maximum egg production may have been delayed, resulting in a shorter spawning period, less prey availability, and thus smaller fish weight and length (e.g. Watanabe \&Yatsu 2004). This was indeed the case in June 1991 during a survey of eggs and larvae, when the water temperature observed in the upper $5 \mathrm{~m}$ was 1.5 to $2.0^{\circ} \mathrm{C}$ less than the long-term average (Niermann et al. 1994). Similarly, a cooling of approximately $1.5^{\circ} \mathrm{C}$ in winter temperature during the first half of the $1970 \mathrm{~s}$ may have counter-balanced the effect of increasing eutrophication-induced productivity and thus may have contributed to the quasi-stability of the moderate stock regime. Conversely, a rise of approximately 1.0 to $1.2^{\circ} \mathrm{C}$ in winter SST during 1964 to 1970 and 1976 to 1981, respectively (Fig. 1), may have supported the anchovy stock transitions TR1 and TR2.

The role of turbulence on fish stock changes is a more complex issue. It may have an overall positive or negative effect on fish feeding, depending on its intensity and predator-prey behaviors (Megrey \& Hinckley 2001). Its beneficial effect was suggested to be the enhancement of encounter rates by means of a turbulence-avoidance strategy in juveniles and adult fishes (Franks 2001); a similar mechanism was also emphasized for the Black Sea small pelagics and gelatinous species by Shushkina et al. (1998). The detrimental effect of turbulence was related to reductions in pursuit success and capture ability of encountered prey and the production of new prey, and dispersion of patches of existing prey (Wroblewski 1984, MacKenzie \& Kiorboe 2000) particularly under highly turbulent conditions. On the basis of these studies, the role of turbulence may be particularly critical to the survival and growth of juvenile and adult anchovy and gelatinous species during highly turbulent winter conditions with limited prey availability. The same may also apply, to a certain extent, to larval stages of anchovy in summer months, because the relatively cold water of the subthermocline layer and strong temperature stratification may prevent them from moving from the surface mixed layer into the turbulence-free zone of the water column. Studying density-dependent impacts of these 
climate-induced changes on long-term anchovy stock changes and of anchovy-gelatinous interactions is not a straightforward task. It requires extension of the model by incorporating detailed mixed layer and entrainment dynamics, parameterization of turbulence, and temperature effects on encounter, ingestion, and growth rates of anchovy populations.

Acknowledgements. This study is a contribution to EU 6th Framework projects SESAME (contract no. 036949-2) and ETC/Water (Contract no. EEA/ADS/06/001-Water), Turkish Scientific and Technological Research Council Project 104Y289, NATO-CLG Project 982453, and the Black Mode Project of the Marie-Curie Intra-European Fellowship Programme (to B.S.). We thank the anonymous reviewers for their helpful comments and suggestions.

\section{LITERATURE CITED}

Alheit J (1989) Comparative spawning biology of anchovies, sardines, and sprats. Rapp Cons Int Explot Mer 191:7-14

Anderson CNK, Hsieh CH, Sandin SA, Hewitt R and others (2008) Why fishing magnifies fluctuations in fish abundance. Nature 452:835-839

Attrill MJ, Power M (2002) Climatic influence on a marine fish assemblage. Nature 417:275-278

Bakun A (2006) Wasp-waist populations and marine ecosystem dynamics: Navigating the 'predator pit' topographies. Prog Oceanogr 68:271-288

Basilone G, Guisande C, Patti B, Mazzola S and others (2006) Effect of habitat conditions on reproduction of the European anchovy (Engraulis encrasicolus) in the Strait of Sicily. Fish Oceanogr 15:271-280

Berdnikov SV, Selyutin VV, Vasilchenko VV, Caddy JF (1999) Trophodynamic model of the Black and Azov Sea pelagic ecosystem: consequences of the comb jelly, Mnemiopsis leidyi, invasion. Fish Res 42:261-289

Bilgin S (2006) Evaluation of the fishery biology of anchovy Engraulis encrasicolus along the Turkish Black Sea coast during 1985-2005. Erciyes Univ Fen Bilimleri Enstitüsü Dergisi 22:213-222 (in Turkish)

Bilio M, Niermann U (2004) Is the comb jelly really to blame for it all? Mnemiopsis leidyi and the ecological concerns about the Caspian Sea. Mar Ecol Prog Ser 269:173-183

Bulgakova YV (1996) Feeding in the Black Sea anchovy: diet composition, feeding behaviour, feeding periodicity and daily rations. Sci Mar 60(Suppl 2):283-284

> Castro LR, Cowen RK (1991) Environmental factors affecting the early life history of bay anchovy Anchoa mitchilli in Great South Bay, New Yok. Mar Ecol Prog Ser 76: 235-247

Cokacar T, Oguz T, Kubilay N (2003) Interannual variability of the early summer coccolithophore blooms in the Black Sea: impacts of anthropogenic and climatic factors. DeepSea Res I 51:1017-1031

Cowan JH Jr, Houde ED, Rose KA (1996) Size-dependent vulnerability of marine fish larvae to predation: an individualbased numerical experiment. ICES J Mar Sci 53:23-37

Daskalov GM (2002) Overfishing drives a trophic cascade in the Black Sea. Mar Ecol Prog Ser 225:53-63

> Daskalov GM (2003) Long-term changes in fish abundance and environmental indices in the Black Sea. Mar Ecol Prog Ser 255:259-270

> Diehl S, Feibel M (2000) Effects of enrichment on three-level food chains with omnivory. Am Nat 155:200-216
Dulcic J (1997) Growth of anchovy Engraulis encrasicolus (L.), larvae in the North Adriatic Sea. Fish Res 31:189-195

Finenko GA, Abolmasova GI, Romanova ZA (1995) Feeding, respiration, and growth of the ctenophore Mnemiopsis mccradyi in relation to grazing conditions. Russ J Mar Biol 21:283-287

Franks PJS (2001) Turbulence avoidance: an alternate explanation for turbulence-enhanced ingestion rates in the field. Limnol Oceanogr 46:959-963

Fulton EA, Smith ADM, Johnson CR (2003) Mortality and predation in ecosystem models: Is it important how these are expressed? Ecol Model 169:157-178

Funamoto T, Aoki I, Wada Y (2004) Reproductive characteristics of Japanese anchovy, Engraulis japonicus, in two bays of Japan. Fish Res 70:71-81

Garcia A, Palomera I (1996) Anchovy early life history and its relation to its surrounding environment in the Western Mediterranean basin. Sci Mar 60 (Suppl 2):155-166

García-Lafuente J, García A, Mazzola S, Quintanilla L, Delgado A, Cuttita A, Patti B (2002) Hydrographic phenomena influencing early life stages of the Sicilian Channel anchovy. Fish Oceanogr 11:31-44

Gordina AD, Niermann U, Kideys AE, Subbotin AA, Artyomov YG, Bingel F (1998) State of summer ichtyoplankton of the Black Sea. In: Ivanov LI, Oguz T (eds) Ecosystem modeling as a management tool for the Black Sea, Vol 1. Kluwer Academic Publishers, Dordrecht, p 367-378

Grégoire M, Lacroix G (2003) Exchange processes and nitrogen cycling on the shelf and continental slope of the Black Sea basin. Glob Biogeochem Cycles 17:1073

> Grégoire M, Soetaert K, Nezlin N, Kostianoy A (2004) Modeling the nitrogen cycling and plankton productivity in the Black Sea using a three-dimensional interdisciplinary model. J Geophys Res 109:C05007

Gücü AC (2002) Can overfishing be responsible for the successful establishment of Mnemiopsis leidyi in the Black Sea? Estuar Coast Shelf Sci 54:439-451

Hart DR (2002) Intraguild predation, invertebrate predators, and trophic cascades in lake food webs. J Theor Biol 218: 111-128

$>$ Holt RD, Polis GA (1997) A theoretical framework for intraguild predation. Am Nat 149:745-764

Ivanov L, Beverton RJH (1985) The fishery resources of the Mediterranean. Part 2: Black Sea. GFCM Studies and Reviews 60, FAO, Rome

Ivanov L, Panayotova M (2001) Determination of the Black Sea anchovy stocks during the period $1968-1993$ by Ivanov's combined method, Proc Inst Oceanol, Bulg Acad Sci 3:128-154

Kideys AE (2002) Fall and rise of the Black Sea ecosystem. Science 297:1482-1484

> Kideys AE, Gordina AD, Bingel F, Niermann U (1999) The effect of environmental conditions on the distribution of eggs and larvae of anchovy (Engraulis encrasicolus L.) in the Black Sea. ICES J Mar Sci 56 (Suppl):58-64

> Konovalov SK, Murray JW (2001) Variations in the chemistry of the Black Sea on a time scale of decades (1960-1995). J Mar Sys 31:217-243

Kremer P, Reeve MR (1989) Growth dynamics of a ctenophore (Mnemiopsis) in relation to variable food supply II: carbon budgets and growth model. J Plankton Res 11:553-574

Kuijper LDJ, Kooi BW, Zonneveld C, Kooijman SALM (2003) Omnivory and food web dynamics. Ecol Model 163:19-32

> Lancelot C, Staneva J, Van Eeckhout D, Beckers JM, Stanev E (2002) Modeling the impact of the human forcing on the ecological functioning of the northwestern Black Sea. Estuar Coast Shelf Sci 54:473-500 
Lebedeva LP, Shushkina EA (1994) The model investigation of the Black Sea plankton community caused by Mnemiopsis. Oceanology (Mosc) 34:79-87

Lisovenko LA, Andrianov DP (1996) Reproductive biology of anchovy (Engraulis encrasicolus ponticus Alexandrov 1927) in the Black Sea. Sci Mar 60(Suppl):209-218

Lisovenko LA, Andrianov DP, Bulgakova YV (1997) Reproductive ecology of the Black Sea anchovy Engraulis encrasicolus ponticus II: quantitative parameters of spawning. J Ichthyol 37:639-646

Lucas CH (2001) Reproduction and life history strategies of the common jellyfish, Aurelia aurita, in relation to its ambient environment. Hydrobiologia 451:229-246

> Luo J, Brandt SB (1993) Bay anchovy Anchoa mitchilli production and consumption in mid-Chesapeake Bay based on a bioenergetic model and acoustic measures of fish abundance. Mar Ecol Prog Ser 98:223-236

MacKenzie BR, Kiorboe T (2000) Larval fish feeding and turbulence: a case for the downside. Limnol Oceanogr 45 : $1-10$

> MacKenzie BR, Koster FW (2004) Fish production and climate sprat in the Baltic Sea. Ecology 85:784-794

> Martindale MQ (1987) Larval reproduction in the ctenophore Mnemiopsis mccradyi (order Lobata). Mar Biol 94:409-414

McDermot D, Rose KA (2000) An individual-based model of lake fish communities: application to piscivore stocking in Lake Mendota. Ecol Model 125:67-102

Megrey BA, Hinckley S (2001) Effect of turbulence on feeding of larval fishes: a sensitivity analysis using an individualbased model. ICES J Mar Sci 58:1015-1029

Megrey BA, Rose KA, Klumb RA, Hay DE, Werner FE, Eslinger DL, Smith SL (2007) A bioenergetic-based population dynamics model of pacific herring (Clupea harengus pallasi) coupled to a lower trophic level nutrientplankton-zooplankton model: description, calibration, and sensitivy analysis. Ecol Model 202:144-164

Mikaelyan AS (1997) Long-term variability of phytoplankton communities in open Black Sea in relation to environmental changes. In: Ozsoy E, Mikaelyan AS (eds) Sensitivity to change: Black Sea, Baltic Sea and North Sea. NATO-ASI Series, Environment, Vol 27, Kluwer Academic Publishers, Dordrecht, p 105-116

Millan M (1999) Reproductive characteristics and condition status of anchovy Engraulis encrasicolus L. from the Bay of Cadiz (SW Spain). Fish Res 41:73-86

Monteiro RSO (2000) Fish growth modeling: growth of the European anchovy (Engraulis encrasicolus) in the Tagus estuary (Portugal). Thesis for Diploma Eruditionum Altarum, Universidad de las Palmas de Gran Canaria

Mullon C, Freon P, Parada C, van der Lingen C, Huggett J (2003) From particles to individuals: modelling the early stages of anchovy (Engraulis capensis/encrasicolus) in the southern Benguela. Fish Oceanogr 12:396-406

Mutlu E, Bingel F, Gücü AC, Melnikov VV, Niermann U, Ostr NA, Zaika VE (1994) Distribution of the new invader Mnemiopsis sp. and the resident Aurelia aurita and Pleurobrachia pileus populations in the Black Sea in the years 1991-1993. ICES J Mar Sci 51:407-421

> Mylius SD, Klumpers K, de Roos AM, Persson L (2001) Impact of intraguild predation and stage structure on simple communities along a productivity gradient. Am Nat 158: 259-276

> Niermann U, Bingel F, Gorban A, Gordina AD and others (1994) Distribution of anchovy eggs and larvae (Engraulis encrasicolus Cuv.) in the Black Sea in 1991-1992. ICES J Mar Sci 51:395-406

North EW, Houde ED (2004) Distribution and transport of bay anchovy (Anchoa mitchilli) eggs and larvae in Chesapeake Bay. Estuar Coast Shelf Sci 60:409-429

> Oguz T (2007) Nonlinear response of Black Sea pelagic fish stocks to over-exploitation. Mar Ecol Prog Ser 345: 211-228

> Oguz T, Gilbert D (2007) Abrupt transitions of the top-down controlled Black Sea pelagic ecosystem during 19602000: evidence for regime shifts under strong fishery exploitation and nutrient enrichment modulated by climateinduced variations. Deep-Sea Res Part I 54:220-242

Oguz T, Merico A (2006) Factors controlling the summer Emiliania huxleyi bloom in the Black Sea: a modeling study. J Mar Syst 59:173-188

> Oguz T, Malanotte-Rizzoli P, Ducklow HW (2001) Simulations of phytoplankton seasonal cycle with multi-level and multi-layer physical-ecosystem models: the Black Sea example. Ecol Model 144:295-314

Oguz T, Dippner JW, Kaymaz Z (2006) Climatic regulation of the Black Sea hydro-meteorological and ecological properties at interannual-to-decadal time scales. J Mar Syst 60: $235-254$

> Ottersen G, Planque B, Belgrano A, Post E, Reid PC, Stenseth NC (2001) Ecological effects of the North Atlantic Oscillation. Oecologia 128:1-14

Palomera I, Olivar MP, Salat J, Sabates A, Coll M, Garcia A, Morales-Nin B (2007) Small pelagic fish in the NW Mediterranean Sea: an ecological view. Prog Oceanogr 74: 377-396

Panov BN, Chashchin AK (1990) Aspects of the water structure dynamics in the southern Black Sea as prerequisites for the formation of winter aggregations of Black Sea anchovy off the coast of Georgia. Oceanology (Mosc) 30:242-247

Peck MA, Daewel U (2007) Physiologically based limits to food consumption, and individual-based modeling of foraging and growth of larval fishes. Mar Ecol Prog Ser 347: $171-183$

Prodanov K, Mikhaylov K, Daskalov G, Maxim K and others (1997) Environmental management of fish resources in the Black Sea and their rational exploitation. GFCM Stud Rev 68:1-178

> Purcell JE (2005) Climate effects on formation of jellyfish and ctenophore blooms: a review. J Mar Biol Assoc UK 85: 461-476

Purcell JE, Arai MN (2001) Interactions of pelagic cnidarians and ctenophores with fish: a review. Hydrobiologia 451: $27-44$

Purcell JE, Shiganova TA, Decker MB, Houde ED (2001) The ctenophore Mnemiopsis in native and exotic habitats: U.S. estuaries versus the Black Sea basin. Hydrobiologia 451: $145-176$

Revilla T (2002) Effects of intraguild predation on resource competition. J Theor Biol 214:49-62

Rilling GC, Houde ED (1999) Regional and temporal variability in growth and mortality of bay anchovy, Anchoa mitchilli, larvae in Chesapeake Bay. Fish Bull 97:555-569

Rose KA, Cowan JH, Clark ME, Houde ED, Wang SB (1999) An individual-based model of bay anchovy population dynamics in the mesohaline region of Chesapeake Bay. Mar Ecol Prog Ser 185:113-132

Samsun O, Samsun N, Kalayci F, Bilgin S (2006) A study on recent variations in the population structure of European anchovy (Engraulis encrasicolus L., 1975) in the southern Black Sea. Ege Univ J Fish Aquat Sci 23:301-306

Satilmis HH, Gordina AD, Bat L, Bircan R, Culha M, Akbulut M, Kideys AE (2003) Seasonal distribution of fish eggs and larvae off Sinop (the southern Black Sea) in 1999-2000. Acta Oecol 24:S275-S280 
Schulman G, Yuneva TV (2002) Fishes as indicators of the Black Sea and Mediterranean ecosystems. In: Yilmaz EA, Salihoglu I, Mutlu E (eds) Oceanography of the eastern Mediterranean and Black Sea. Abstracts, 2nd Int Conf, Ankara

Shiganova TA, Bulgakova YV (2000) Effects of gelatinous plankton on Black Sea and Sea of Azov fish and their food resources. ICES J Mar Sci 57:641-648

Shiganova TA, Mirzoyan ZA, Studenikina EA, Volovik SP and others (2001) Population development of the invader ctenophore Mnemiopsis leidyi in the Black Sea and other seas of the Mediterranean basin. Mar Biol 139:431-445

Shushkina EA, Musayeva EI (1983) The role of jellyfish in the energy system of Black Sea plankton communities. Oceanology (Mosc) 23:92-96

Shushkina EA, Vinogradov ME, Lebedeva LP, Oguz T, Nezlin NP, Dyakonov VY, Anokhina LL (1998) Studies of structural parameters of planktonic communities of the open part of the Black Sea relevant to ecosystem modeling. In: Ivanov LI, Oguz T (eds) Ecosystem modeling as a management tool for the Black Sea, Vol 1. NATO Science Partnership Sub-ser 2, Vol 47. Kluwer Academic, Norwell, MA, p 311-326

Somarakis S, Palomera I, Garcia A, Quintanilla L, Koutsikopoulos C, Uriarte A, Motos L (2004) Daily egg production of anchovy in European waters. ICES J Mar Sci 61: 944-958

Sorokin YI (2002) The Black Sea: ecology and oceanography. Backhuys Publishers, Leiden

Tian Y, Akamine T, Suda M (2004) Modeling the influence of oceanic-climatic changes on the modelling of the dynamics of Pacific saury in the northwesterrn Pacific using a life cycle model. Fish Oceanogr 13(Suppl 1):125-137

Uckun D, Akalin S, Togulga M (2005) Investigations of the age and growth of anchovy (Engraulis encrasicolus L., 1958) in Izmir Bay. Ege Univ J Fish Aquat Sci 22:281-285 van de Wolfshaar KE, de Ross AM, Persson L (2006) Sizedependent interactions inhibit coexistence in intraguild predation systems with life-history omnivory. Am Nat 168: 62-75

Vinogradov ME, Shushkina EA, Musaeva EI, Sorokin PY (1989) A newly acclimated species in the Black Sea: the ctenophore Mnemiopsis leidyi (Ctenophora: Lobata). Oceanology (Mosc) 29:220-224

Vinogradov ME, Shushkina EA, Bulgakova YV, Serobaba II (1996) The consumption of zooplankton by the comb jelly Mnemiopsis leidyi and pelagic fishes in the Black Sea. Oceanology (Mosc) 35:569-573

Vinogradov ME, Shushkina EA, Lukasheva TA (2005) Population dynamics of the ctenophores Mnemiopsis leidyi and Boroe ovata as a predator-prey system in the near-shore communities of the Black Sea. Oceanology (Mosc) 45 (Suppl 1):S161-S167

> Wang SB, Cowan JH, Rose KA, Houde ED (1997) Individualbased modeling of recruitment variability and biomass production of bay anchovy in mid-Chesapeake Bay. J Fish Biol 51(Suppl A):101-120

Watanabe C, Yatsu A (2004) Effects of density-dependence and sea surface temperature on interannual variation in length-at-age of chub mackerel (Scomber japonicus) in the Kuroshio-Oyashio area during 1970-1997. Fish Bull (Wash DC) 102:196-206

Wroblewski JS (1984) Formulation of growth and mortality of larval northern anchovy in a turbulent feeding environment. Mar Ecol Prog Ser 20:13-22

Zaitsev YP (1992) Recent changes in the trophic structure of the Black Sea. Fish Oceanogr 1:180-189

Zaitsev YP, Mamaev V (1997) Marine biological diversity in the Black Sea: a study of change and decline. GEF Black Sea Environmental Programme, United Nations Publications, Istanbul

Appendix 1. Explicit form of all terms used in the mathematical formulation of the LTL model

For each phytoplankton group $(i=1,2,3)$, the growth in each layer $(k=1,2)$ is defined by

$$
U_{i, k}=r_{\mathrm{P} i} \times f_{k}\left(I_{k}\right) \times f_{k}\left(T_{k}\right) \times f_{i, k}\left(N_{k}\right) \times \mathrm{P}_{i, k}
$$

where $r_{\mathrm{P} i}$ denotes the maximum specific growth rate at maximum temperature, and $f_{k}(I), f_{k}(T), f_{i k}\left(N_{k}\right)$ are the limitation functions due to light, temperature, and nitrogen uptake, respectively. The nitrogen limitation function follows the Monod kinetics

$$
f_{i, k}\left(N_{k}\right)=N_{k} /\left(K_{N i}+N_{k}\right)
$$

where $K_{N}$ represents the half saturation constant for nitrate uptake (Table 1). The light limitation is represented by the tangent hyperbolic function

$$
f_{k}\left(I_{k}\right)=\tanh \left[a_{\mathrm{I}}<I_{k}>\right]
$$

where the constant parameter $a_{\mathrm{I}}$ signifies the slope of the P-I curve (Table 4 ), and $\left\langle I_{k}>\right.$ is the mean photosynthetically available solar radiation in the layers. Assuming $I(z)$ decays exponentially with depth compared to its surface value $I_{\mathrm{s}}$ according to the extinction parameter $k_{\mathrm{e}}=k_{\mathrm{w}}+k_{\mathrm{c}} \times \Sigma \mathrm{P}_{i}$ (Table 4), $\left\langle I_{k}\right\rangle$ for the mixed and sub-thermocline layers is expressed by

$$
<I_{1}>=\frac{I_{\mathrm{s}}}{k_{\mathrm{e}} h_{1}}\left(1-\mathrm{e}^{-k_{\mathrm{e}} h_{1}}\right) \quad<I_{2}>=\frac{I_{s} \mathrm{e}^{-k_{\mathrm{e}} h_{1}}}{k_{\mathrm{e}} h_{2}}\left(1-\mathrm{e}^{-k_{\mathrm{e}} h_{2}}\right)
$$

The temperature limitation function for the phytoplankton growth is given by

$$
f_{k}\left(T_{k}\right)=Q_{10 \mathrm{P}}^{\left(T_{k}-T_{\max }\right) / T_{\mathrm{Pref}}}
$$

where we set $T_{\max }=25^{\circ} \mathrm{C}$, and $Q_{10 \mathrm{P}}=1.5, T_{\text {Pref }}=15^{\circ} \mathrm{C}$ (Table 4).

The grazing of phytoplankton by mesozooplankton $\left(\mathrm{Z}_{1}\right)$ and microzooplankton $\left(Z_{2}\right)$ for each layer $(k=1,2)$ is expressed in a Holling Type III functional form by

$$
\begin{gathered}
G_{\mathrm{Z} 2, k}^{\mathrm{P} i}=r_{\mathrm{Z} 2} \frac{s_{i} \mathrm{P}_{i, k}^{2}}{\left(K_{\mathrm{Z} 2}^{2}+\sum_{i=1}^{3} s_{i} \mathrm{P}_{i, k}^{2}\right)} \mathrm{Z}_{2, k} \\
G_{\mathrm{Z} 1, k}^{\mathrm{P} i}=r_{\mathrm{Z} 1} \frac{s_{i} \mathrm{P}_{i, k}^{2}}{\left(K_{\mathrm{Z} 1}^{2}+s_{4} \mathrm{Z}_{2, k}^{2}+\sum_{i=1}^{3} s_{i} \mathrm{P}_{i, k}^{2}\right)} \mathrm{Z}_{1, k}
\end{gathered}
$$

where $r_{\mathrm{Z}}$ and $K_{\mathrm{Z}}$, respectively, denote the maximum grazing rate and half saturation constant of phytoplankton biomass at which zooplankton grazing attains half of its maxium value (Table 2), and $s_{i}$ is the food preference coefficient (Table 3 ) of prey type $i$ to zooplankton type $j$. Mesozooplankton grazing on microzooplankton is given by 
Appendix (continued)

$$
G_{\mathrm{Z} 1, \mathrm{k}}^{\mathrm{Z} 2}=r_{\mathrm{Z} 1} \frac{s_{4} \mathrm{Z}_{2, \mathrm{k}}^{2}}{\left(K_{\mathrm{Z} 1}^{2}+s_{4} \mathrm{Z}_{2, \mathrm{k}}^{2}+\sum_{i=1}^{3} s_{i} \mathrm{P}_{i, k}^{2}\right)} \mathrm{Z}_{1, k}
$$

Because weight growth of gelatinous species does not become saturated at high food concentrations (Lebedeva \& Shushkina 1994), their consumption of micro- and mesozooplankton in each layer is expressed by a linear function (Lancelot et al. 2002)

$$
G_{\mathrm{Z} 3, k}^{\mathrm{Zi}}=r_{\mathrm{Z} 3} \frac{s_{i} \mathrm{Z}_{i, k}}{K_{\mathrm{Z} 3}} \mathrm{Z}_{3, k}
$$

where $s_{i}$ is the food preference coefficient of gelatinous carnivores on meso- and microzooplankton (Table 3), and $r_{\mathrm{Z} 3}^{*}=r_{\mathrm{Z} 3} / K_{\mathrm{Z} 3}\left(\mathrm{~m}^{3} \mathrm{mmol}^{-1} \mathrm{~d}^{-1}\right)$ defines the clearance rate.

Meso- and microzooplankton exchange between the mixed and sub-thermocline layers at a constant rate $v_{\mathrm{z}}$ (Tables 1 \& 2) times the biomass difference in the layers:

$$
M_{k}^{Z_{i}}=\sum_{j=1}^{2} v_{\mathrm{Z}} \times\left(\mathrm{Z}_{i, j}-\mathrm{Z}_{i, k}\right)
$$

where the subscripts $k$ and $j=1$ and 2 denote the mixed and sub-thermocline layer, respectively. No exchange is allowed between the sub-thermocline and the biologically inactive subsurface source layer. A similar expression also applies to 3 phytoplankton groups.

The nitrate flux between the layers ( $k=1$ and 2$)$ is described by

$$
M_{k}^{\mathrm{N}}=\left(v_{\mathrm{N}}+w_{\mathrm{e}}\right) \times\left[\left(N_{C}-N_{k}\right)+\sum_{j=1}^{2}\left(N_{j}-N_{k}\right)\right]
$$

where $v_{\mathrm{N}}$ and $w_{\mathrm{e}}$ denote the diffusion and entrainment rates, respectively (Table 4 ). The first term within square brackets is the nitrate flux supplied from the source layer into the sub-thermocline layer (for $k=2$ ) and the mixed layer (for $k=1$ ) when the mixed layer approaches the base of the euphotic zone (i.e. $h_{1}=45 \mathrm{~m}$ ). Otherwise, the nitrate flux is only supplied into the sub-thermocline layer. The second term within square brackets represents the nitrate transport between the mixed and sub-thermocline layers. During the shallowing phase of the mixed layer (i.e. $w_{\mathrm{e}}=0$ ), nitrate flux due to the entrainment process does not take place in the system. 